\title{
Towards dynamics in flood risk assessment
}

\author{
B. Mazzorana ${ }^{1}$, L. Levaggi ${ }^{2}$, M. Keiler ${ }^{3}$, and S. Fuchs ${ }^{4}$ \\ ${ }^{1}$ Department of Hydraulic Engineering - Abteilung Wasserschutzbauten, Autonomous Province of Bolzano, Italy, \\ Cesare Battisti Str. 23, 39100 Bolzano, Italy \\ ${ }^{2}$ Faculty of Science and Technology, Free University of Bolzano, Universitätsplatz 5, 39100 Bolzano, Italy \\ ${ }^{3}$ Institute of Geography, University of Bern, Hallerstr. 12, 3012 Bern, Switzerland \\ ${ }^{4}$ Institute of Mountain Risk Engineering, University of Natural Resources and Life Sciences, Peter Jordan Str. 82, \\ 1190 Wien, Austria
}

Correspondence to: B. Mazzorana (bruno.mazzorana@ provinz.bz.it)

Received: 4 November 2011 - Revised: 4 October 2012 - Accepted: 17 October 2012 - Published: 29 November 2012

\begin{abstract}
As a consequence of flood impacts, communities inhabiting mountain areas are increasingly affected by considerable damage to infrastructure and property. The design of effective flood risk mitigation strategies and their subsequent implementation is crucial for a sustainable development in mountain areas. The assessment of the dynamic evolution of flood risk is the pillar of any subsequent planning process that is targeted at a reduction of the expected adverse consequences of the hazard impact. Given these premises, firstly, a comprehensive method to derive flood hazard process scenarios for well-defined areas at risk is presented. Secondly, conceptualisations of a static and dynamic flood risk assessment are provided. These are based on formal schemes to compute the risk mitigation performance of devised mitigation strategies within the framework of economic costbenefit analysis. In this context, techniques suitable to quantify the expected losses induced by the identified flood impacts are provided.
\end{abstract}

\section{Introduction}

In recent years, increasing numbers of natural hazards and associated losses have shown to the European Commission and the Member States of the European Union the paramount importance of assessing flood risks to protect the environment and the citizens (Barredo, 2007). There is some scientific evidence of an increase in mean precipitation and precipitation intensity, which implies that extreme flood events might become more frequent (Keiler et al., 2010). In parallel, exposure to floods might increase across Europe due to population dynamics and the associated economic development in flood-prone areas, which affects flood vulnerability. Therefore, even without taking climate change into account an increase of flood disasters in Europe may be expected (Mitchell, 2003).

The Directive on the Assessment and Management of Flood Risks addressed to the Member States (Floods Directive) was issued in 2007 (Commission of the European Communities, 2007) as one of the three components of the European Action Programme on Flood Risk Management (Commission of the European Communities, 2004). Within this Directive, flood events (defined in their broadest sense, including both water and sediment transport processes) have been officially acknowledged to be natural phenomena which cannot be prevented. Such events have the potential to severely compromise economic development and to undermine the economic activities of the Community due to an increase of human activities in floodplains and the reduction of natural water retention by land use practices. As a result, an increase in the likelihood and adverse impacts of flood events is expected. Therefore, concentrated action is needed at the European level to avoid severe impacts on human life and property. In order to have an effective tool available for information on flood risk, as well as a valuable basis for priority setting and further technical, financial and political decisions regarding flood risk mitigation and management, it is necessary to establish flood risk maps which show the potential adverse consequences associated with different flood scenarios.

In this paper, flood risk is defined taking a natural scientific viewpoint; it is expressed by a risk equation which 
includes the probability of occurrence of a flood hazard scenario $\left(p_{S i}\right)$, the value of elements at risk exposed $\left(A_{O j}\right)$, the related vulnerability in dependence on the flood hazard scenario $\left(v_{O j, S i}\right)$, and the probability of exposure of elements at risk to the flood hazard scenario $\left(p_{O j}, S i\right)$.

$R_{i, j}=f\left(p_{S i}, A_{O j}, v_{O j, S i}, p_{O j, S i}\right)$

This risk concept, however, is static while both hazard scenarios and elements at risk exposed show a dynamic evolution. Risk related to flood hazards is subject to temporal changes since the risk-influencing factors are variable over time. Firstly, the design discharge - as one pillar of the flood hazard scenario - may be altered due to changes in the precipitation regime, in the retention area available and due to changes in the land use activities (Keiler et al., 2010). Moreover, one fundamental characteristic of mountain catchments is a temporal dynamic in sediment availability, which results in highly variable discharge behaviour. Secondly, the elements at risk exposed change over time, which results in a long-term increase for many mountain communities in Europe and a superimposed short-term fluctuation due to people commuting into these mountain regions (Fuchs et al., 2004, 2005; Keiler, 2004; Keiler et al., 2005, 2006; Zischg et al., 2005).

In Europe, strategies to prevent or to reduce the effects of flood hazards in mountain areas trace back to the mediaeval times, official authorities were only founded in the late 19 th century based on first national legal regulations (Länger, 2003). Until the early 20th century, protection against flood hazards was dominated by implementing permanent measures in the upper parts of the catchments to retain solids from erosion, and by silvicultural efforts to afforest high altitudes. Since the 1950s, such conventional mitigation concepts, which aimed at decreasing both the magnitude and the frequency of flood events, were increasingly complemented by other technical mitigation measures aiming at the deflection of hazard processes into areas not used for settlements. Watershed management measures, forest-biological and soil bio-engineering measures, as well as technical measures were implemented (Holub and Fuchs, 2009; Holub et al., 2012). According to the approach of disposition management (reducing the probability of occurrence of a hazard) and event management (interfering the transport process of the hazard itself), a range of technical measures is available for active prevention (ONR, 2009). However, structural mitigation inevitably has limitations, and the analysis of the most recent flood events in European mountain regions (Keiler et al., 2010) highlighted considerable shortcomings in the current procedures used for natural hazard risk assessment due to inherent system dynamics. Concerning the hazard assessment in particular, conventional numerical hydrodynamic and morphodynamic river models are not always reliable in precisely predicting the process pattern since internal system dynamics, such as changing solids concentration along the flow path, are not sufficiently mirrored (Mazzorana et al., 2012). Especially the effects of changing channel morphology over time and the reduction of cross-sectional areas due to clogging were found to significantly amplify process magnitudes and frequencies (Comiti et al., 2008). In order to improve risk analyses, flood hazard scenarios need to be re-established based on such issues.

Therefore, the risk assessment approach has to be tailored. Recently, a nested-scenario approach was proposed by Mazzorana and Fuchs (2010a), which is composed of different levels: (1) natural hazard scenarios, (2) exposure scenarios, (3) vulnerability scenarios, and (4) analyses of values at risk, resulting in (5) risk scenarios. According to the conceptualisation of risk, these nested components have multiple functional dependencies among each other, resulting in compound intersections both in time and space.

The design of appropriate risk mitigation strategies requires a profound knowledge of the temporal evolution of flood risk. In this context it is essential to identify the crucial "risk kernels", namely those tipping patterns that determine significant amplifications in terms of the hazard level, such as for example bridge clogging and levee failure (Mazzorana et al., 2011).

A subsequent procedural step necessary is the generation of risk mitigation strategies directed at maximising the reduction of risk according to the target system defined, and in compliance with the guidelines of the Floods Directive (Commission of the European Communities, 2007). A series of heuristics to design optimal flood risk mitigation strategies and a logical structure to describe essential elements of flood risk mitigation strategies have been proposed (Mazzorana and Fuchs, 2010b) and need to be further refined within a coherent framework of economic cost-benefit analyses in order to fulfil the requirements of economic efficiency of risk mitigation alternatives.

In this paper, along with the objective to produce a reliable delineation of hazard zones, a functional distinction between the loading and the response system (LS and RS, respectively) is made. The loading system encompasses the confined part of a catchment where discharge, sediment load and wood fluxes are generated (i.e. the erosion and denudationdominated areas), and the response system, including the unconfined areas that are subject to flooding (i.e. flooding and accumulation dominated area) (Hübl et al., 2003; Mazzorana and Fuchs, 2010b; Mazzorana et al., 2011). In a subsequent step, a methodological overview is provided which explains the necessary steps, such as process routing along the stream system and integrating the knowledge derived from models and expert-based judgment in order to derive consistent and fully probabilised scenarios (Mazzorana and Fuchs, 2010a).

Since the outcomes of scenario development for the loading system provide the input for the response system analysis, a synthesis of the methodological steps to analyse process propagation in the response system is presented. Emphasis will be put on the understanding of the system behaviour regarding two main types of spatial domains, i.e. stochastic 
and quasi-deterministic domains, based on the predictability of their dynamics. Together with the full set of flood hazard propagation scenarios, conceptualisations of static and dynamic flood risk are provided and formal schemes to compute the risk mitigation performance of considered mitigation strategies are given within the framework of economic cost-benefit analyses. Therefore, suitable economic valuation techniques are revisited and discussed in order to quantify the value of assets at risk in monetary terms.

\section{Requirements for a dynamic approach}

The proposed procedural map is shown in Fig. 1. The first step (sub-procedure A) in the proposed procedural roadmap consists in determining consistent flood hazard and risk scenarios. The specific aims are to obtain a spatially explicit representation of the frequency and magnitude (intensity) for each of the underlying hazard scenarios and to quantify the associated consequences in terms of losses with respect to values exposed, and thus risk. The main result is the so-called risk reference prospect, which serves as a basis for a performance comparison between possible risk mitigation alternatives. In this paper emphasis is put on the computational aspects needed to derive flood risk, whereas the full set of specifics related to the determination of the underlying flood hazard scenarios is provided in previous publications (Mazzorana and Fuchs, 2010a; Mazzorana et al., 2012).

The second step (sub-procedure B) includes the generation of risk mitigation strategies aimed at maximising the reduction of flood risk in accordance to the target system. From a methodological perspective, substantial effort has recently been undertaken to systematise the design of risk mitigation strategies and to formulate respective heuristics to be used by the practitioners (Mazzorana and Fuchs, 2010b). For each planned risk mitigation strategy, the system under consideration has to be re-analysed from a hazard and risk assessment perspective. Thus, all analytic steps of sub-procedure 1 have to be repeated in order to explicitly modify the system behaviour either concerning flood hazard process unfolding or concerning the determination of expected consequences on vulnerability and elements at risk exposed.

An essential requirement for the economic assessment of risk mitigation strategies (sub-procedure $\mathrm{C}$ ) is the determination of costs and benefits over the entire life-cycle of a mitigation alternative. Concerning the benefits, in this paper, we limit our assessment to the annual flood risk reduction with respect to the risk reference prospect for property, infrastructure and human lives. At this stage the Net Present Value (NPV) can be determined for each strategy. Based on a ranking of the strategies according to their NPV, the economically most efficient strategy can be identified (Fuchs et al., 2007a) and selected (sub-procedure D).

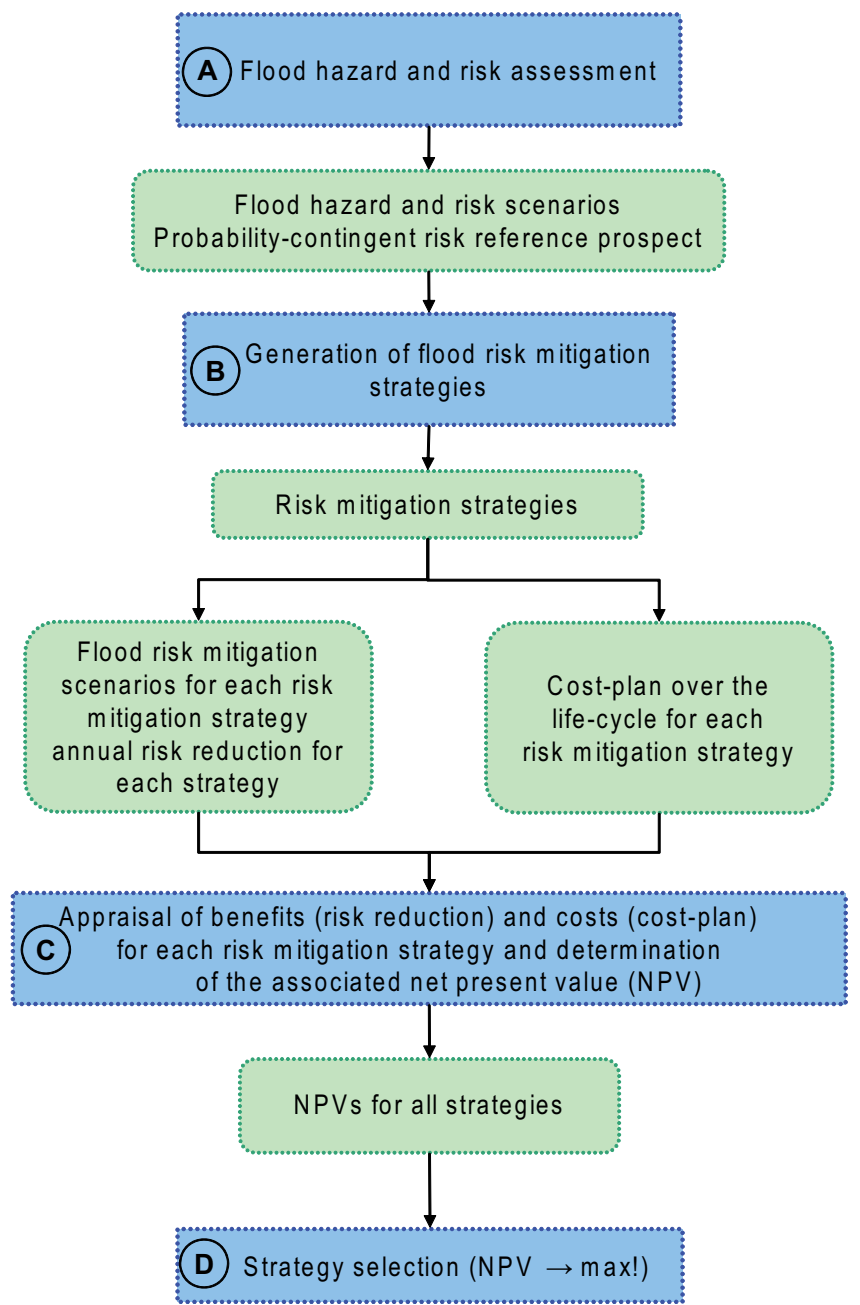

Fig. 1. Procedural roadmap for a comprehensive risk mitigation project assessment based on the concept of Net Present Value (NPV); A, B, C, D: subprocedures.

\section{Hazard assessment}

A series of methodological steps is presented that may be used to assess flood hazards by systematically removing knowledge gaps related to interacting chains typical for hazard processes in mountain streams. A standard system representation scheme is employed, which is based on the distinction between loading systems (LS) and response systems (RS) on the scale of a hydrologic basin. The loading systems represent the spatial domains, i.e. stream channels, which are regularly confined by hillslopes and have a defined flow direction and flow path. The response systems include alluvial or debris fans and floodplains where the channel regularly is unconfined and multiple possible flow directions and flow paths are present.

The developed approach is organised in three tables (Tables 1-3). Table 1 contains a summary of necessary steps for hydrological analysis. In Table 2 the assessment steps 
Table 1. Main steps of the hydrological analysis.

\begin{tabular}{|c|c|c|c|}
\hline \multicolumn{4}{|c|}{ Hydrology } \\
\hline 1 & $\begin{array}{l}\text { Statistical analysis of } \\
\text { extreme rainfall events. }\end{array}$ & $\begin{array}{l}\text { Fit suitable extreme value distributions to the } \\
\text { available time series of annual precipitation } \\
\text { maxima for different rainfall durations. } \\
\text { Assign to each obtained Depth-Duration- } \\
\text { Frequency (DDF) curve, which is identified } \\
\left.\text { by the value triple (RI } a_{j}, n_{j}\right) \text {, where } a_{j} \\
\text { and } n_{j} \text { are the parameters of the } j \text {-th DDF } \\
\text { curve, the associated probability represented } \\
\text { probability, in terms of a defined area under } \\
\text { the probability density curve. The represented } \\
\text { probability density for the } j \text {-th DDF curve, is } \\
\text { equal to } p_{j}=\left(\bar{p}_{j+1}-\bar{p}_{j-1}\right) / 2 \text { for } 1<j< \\
M \text { and } p_{M}=\left(1-\bar{p}_{M}\right)+\left(\bar{p}_{M}-\bar{p}_{M-1}\right) / 2 \text { and } \\
p_{1}=\left(\bar{p}_{1}\right)+\left(\bar{p}_{2}-\bar{p}_{1}\right) / 2 \text { respectively, where } \\
\bar{p}_{j+1} \text { and } \bar{p}_{j-1} \text { are the non-exceedance proba- } \\
\text { bilities associated with the recurrence intervals } \\
\text { RI } \\
j+1 \text { and } \mathrm{RI}_{j-1} \text {. }\end{array}$ & $\begin{array}{l}\text { DDF curves and their associated parameters } \\
\text { corresponding to different recurrence intervals } \\
\text { (RI). } \\
\text { We obtain } j=1, \ldots, M \text { tuples, }\left(\mathrm{RI}_{j}, p_{j}, a_{j}, n_{j}\right) \\
\text { describing the rainfall input in terms of } \\
\text { duration-dependent magnitude and frequency. }\end{array}$ \\
\hline 2 & $\begin{array}{l}\text { Analysis of distributed } \\
\text { catchment hydrology }\end{array}$ & $\begin{array}{l}\text { Run a model for distributed catchment hydrol- } \\
\text { ogy with } j=1, \ldots, M \text { tuples, derived in step } 1 \\
\text { of the procedure, describing the rainfall input } \\
\text { and with distributed information about the hy- } \\
\text { drologic characteristics of the catchment (i.e. } \\
\text { land use, geology, vegetation over, etc.) }\end{array}$ & $\begin{array}{l}\text { For each tuple }-\mathrm{RI}{ }_{j}, p_{j}, a_{j}, n_{j}-\text { the hydrologic } \\
\text { response in terms of runoff is obtained. For- } \\
\text { mally we derive }\left[\mathrm{RI}_{j}, p_{j}, a_{j}, n_{j}, Q_{j}^{\mathrm{W}}(\boldsymbol{x}, t)\right] \\
\text { where } Q_{j}^{\mathrm{W}}(\boldsymbol{x}, t) \text { identifies a water discharge } \\
\text { hydrograph at any desired location }(\boldsymbol{x}) \text { along the } \\
\text { stream network. }\end{array}$ \\
\hline
\end{tabular}

of flood hazard analysis within the loading systems (LS) are presented, and in Table 3 , the analytic steps within the response system (RS) are shown. Each table contains four columns, labelled respectively as "step", "action", "procedural aspects" and "results" in order to facilitate a tracking of the efforts necessary and the corresponding insights gained. Maximum efforts were undertaken to achieve a balance between formal rigor and clarity of exposition, whereas additional information may be accessed through the cited references.

After having probabilised all individual process scenario trajectories in the LS, the boundary conditions for the analysis in the RS are specified as input events in terms of liquid and solid discharges (i.e. water, sediment and drift wood; compare Fig. 2). The statement $I_{q_{j}, j}^{\mathrm{PR}}\left(\boldsymbol{x}_{N}, t\right):=$ $\left[\bar{P}_{q_{j}, j}^{\mathrm{PR}} ; Q_{j}^{\mathrm{W}}\left(\boldsymbol{x}_{N}, t\right) ; Q_{q_{j}, j}^{\mathrm{S}}\left(\boldsymbol{x}_{N}, t\right) ; Q_{q_{j}, j}^{\mathrm{LW}}\left(\boldsymbol{x}_{N}, t\right)\right]$ is used as a formal notation to identify a specific input event. Thereby, $I_{q_{j}, j}^{\mathrm{PR}}\left(\boldsymbol{x}_{N}, t\right)$ is the input event characterised by water, sediment and wood fluxes, symbolised by $Q_{j}^{\mathrm{W}}\left(\boldsymbol{x}_{N}, t\right)$, $Q_{q_{j}, j}^{\mathrm{S}}\left(\boldsymbol{x}_{N}, t\right)$ and $Q_{q_{j}, j}^{\mathrm{LW}}\left(\boldsymbol{x}_{N}, t\right)$ respectively, entering the RS at node $N$ with probability $\bar{P}_{q_{j}, j}^{\mathrm{PR}}$. Throughout, for the input event $I_{q_{j}, j}^{\mathrm{PR}}\left(\boldsymbol{x}_{N}, t\right)$, we use for convenience the notation $I_{q_{j}, j}$.

Nat. Hazards Earth Syst. Sci., 12, 3571-3587, 2012
Depending on the diversity of individual process routing scenario trajectories, $T_{q_{j}, j}^{\mathrm{PR}}$, it may be convenient for the purposes of the response system analysis to reduce the number of input events $I_{q_{j}, j}$ to be considered. Starting from node $N$, it is suggested to track backwards within each process routing scenario tree $\Gamma_{j}^{\mathrm{PR}}$ the individual process routing scenario trajectories $T_{q_{j}, j}^{\mathrm{PR}}$ and cluster those trajectories exhibiting similarity in $Q_{j}^{\mathrm{W}}\left(\boldsymbol{x}_{N}, t\right), Q_{q_{j}, j}^{\mathrm{S}}\left(\boldsymbol{x}_{N}, t\right)$ and $Q_{q_{j}, j}^{\mathrm{LW}}\left(\boldsymbol{x}_{N}, t\right)$ and $T_{q_{j}}^{\mathrm{PR}} \mid\left(\mathrm{ASE}_{i} \leftrightarrow \mathrm{ASE}_{i-1}\right), \forall i$ with $m \leq i<$ $N$. Substantially a reduced set of input events, $I_{\hat{q}_{j}, j}^{\mathrm{PR}}\left(\boldsymbol{x}_{N}, t\right)$, is obtained, where $\hat{q}_{j}$ indicates the reduced number of input events with respect to the previous number $q_{j}$. Having clustered the process routing scenario trajectories that exhibit a satisfactory degree of similarity, the probability to be associated to the resulting representative input event (i.e. selecting within the cluster the worst case trajectory in terms of $\left.Q_{j}^{\mathrm{W}}\left(\boldsymbol{x}_{N}, t\right), Q_{q_{j}, j}^{\mathrm{S}}\left(\boldsymbol{x}_{N}, t\right), Q_{q_{j}, j}^{\mathrm{LW}}\left(\boldsymbol{x}_{N}, t\right)\right)$ is the sum of the probabilities of all trajectories belonging to the cluster $\left\langle\bar{P}_{\hat{q}_{j}, j}^{\mathrm{PR}}\right\rangle_{c}$.

To exemplify the construction of a stochastic spatiotemporal evolution scheme of flood inundation, $E_{\mathrm{RS}} \mid I_{q_{j}, j}$, a response system (RS) is considered that has only two stochastic nodes (i.e. two bridges subject to clogging), $\mathrm{SN}_{1}$ and $\mathrm{SN}_{2}$, 
Table 2. Main process analysis steps in the loading system (LS).

\begin{tabular}{|c|c|c|}
\hline \multicolumn{3}{|c|}{ Procedure for the assessment of flood hazard scenarios within the lo } \\
\hline STEP & ACTION & PROCEDURAL ASPECTS \\
\hline 1 & $\begin{array}{l}\text { Segmentation of the stream network into } \\
\text { channel reaches in order to establish a sim- } \\
\text { plified homogeneous stream system (HSS). }\end{array}$ & $\begin{array}{l}\text { Apply a geomorphological approach based } \\
\text { on a combination of valley morphology, } \\
\text { basin geology, channel confinement, hills- } \\
\text { lope processes, anthropogenic impact and } \\
\text { intervention. }\end{array}$ \\
\hline 2 & $\begin{array}{l}\text { Specification of the flood hydrographs } \\
Q_{j}^{\mathrm{W}}(\boldsymbol{x}, t) \text { at any segmentation node, } i= \\
1, \ldots, N \text {, of the simplified HSS for all given } \\
\mathrm{RI}_{j} \vee p_{j} \text {. }\end{array}$ & $\begin{array}{l}\text { Spatial analysis of the results of distributed } \\
\text { Hydrological Modelling (compare Table 1). }\end{array}$ \\
\hline 3 & $\begin{array}{l}\text { Determination of the geomorphological } \\
\text { channel reach variables (e.g. mean channel } \\
\text { slope, mean channel width, mean floodway } \\
\text { width, descriptors of initial and boundary } \\
\text { condition, identification of adjustment de- } \\
\text { scriptors). }\end{array}$ & $\begin{array}{l}\text { For a comprehensive overview of the pro- } \\
\text { cedural aspects compare Mazzorana and } \\
\text { Fuchs (2010a). The guiding principle is to } \\
\text { treat the underlying physical issues of en- } \\
\text { vironmental interaction as a transformed } \\
\text { initial-boundary value problem to main- } \\
\text { tain the conceptual coherence with the } \\
\text { mathematical-physical problem setting. }\end{array}$ \\
\hline
\end{tabular}


Table 3. Main process analysis steps in the response system (RS).

\begin{tabular}{|c|c|c|c|}
\hline \multicolumn{4}{|c|}{ Analytic steps to deduce the inundation patterns in the response system (RS) } \\
\hline STEP & ACTION & PROCEDURAL ASPECTS & RESULTS \\
\hline 1 & $\begin{array}{l}\text { Delineation of the RS domains (areas } \\
\text { adjacent to channels subject to inunda- } \\
\text { tion/erosion) and precise identification } \\
\text { of the vulnerable RS domains, } \Omega^{\mathrm{RS}} \text {, } \\
\text { containing the relevant assets at risk. }\end{array}$ & $\begin{array}{l}\text { Analysis of the valley (fan) morphology, } \\
\text { channel confinement, valley (fan) substrate. } \\
\text { Analysis of present land use maps, ex- } \\
\text { ploratory investigation to anticipate future } \\
\text { land demands and land use change. Re- } \\
\text { trieval of documentation of past floods } \\
\text { events, analysis to confirm the delineation } \\
\text { of the vulnerable RS domains, } \Omega^{\mathrm{RS}} \text {. }\end{array}$ & $\begin{array}{l}\text { Datasets (i.e digital terrain model, land use, } \\
\text { values at risk, input and validation data for } \\
\text { hydrodynamic flood modelling, dipped ac- } \\
\text { cording to the perimeter of the RS domains. }\end{array}$ \\
\hline 2 & $\begin{array}{l}\text { Identification of the relevant stochastic } \\
\text { nodes (or domains) within the vulnera- } \\
\text { ble RSs. }\end{array}$ & $\begin{array}{l}\text { Identification of bridges, culverts, unreli- } \\
\text { able hydraulic structures (e.g. old levees } \\
\text { and check dams) interacting with the flow } \\
\text { and possibly causing severe consequences } \\
\text { in terms of risk. The analysis entails the } \\
\text { study of past events and the collection of } \\
\text { site-specific expert knowledge. }\end{array}$ & $\begin{array}{l}\text { Spatially identified stochastic nodes (or do- } \\
\text { mains) }-\mathrm{SN}_{k}-k=1, \ldots, K \text { within the } \\
\Omega^{\mathrm{RS}} \text {. Construction of the abstracted re- } \\
\text { sponse system, ARS, corresponding to a do- } \\
\text { main partition of } \Omega^{\mathrm{RS}} \text { in } \mathrm{SN}_{k} \text { and the sur- } \\
\text { rounding quasi-deterministic domain DD } \\
\text { (for a complete treatment of the method and } \\
\text { the logical aspects, compare Mazzorana et } \\
\text { al., 2011). }\end{array}$ \\
\hline 3 & $\begin{array}{l}\text { Determination of the possible sys- } \\
\text { tem states for each stochastic node } \\
\text { (e.g. states, clogged and unclogged in } \\
\text { case of bridges, etc.) and estimation } \\
\text { of process-intensity-contingent state- } \\
\text { transition probabilities. }\end{array}$ & $\begin{array}{l}\text { Analysis based on the type and dimension } \\
\text { of each } \mathrm{SN}_{k} \text {. } \\
\text { Hypothesise possible ranges of loading } \\
\text { conditions in terms of flood intensities and } \\
\text { define parsimoniously a limited number } \\
\text { of relevant states, } \sigma_{h_{1}}, \ldots, \sigma_{H_{k}} \text {, for each } \\
\text { stochastic node } \mathrm{SN}_{k} \text {. } \\
\text { Expert-based judgement is central for the } \\
\text { estimation of state-transition probability, } \\
p\left(\sigma_{h_{i}} \mid\left(\sigma_{h_{j}} \wedge I_{l}\right)\right) \text {, representing the prob- } \\
\text { ability of a transition from } \sigma_{h_{j}} \text { to } \sigma_{h_{i}} \text { at a } \\
\text { process intensity level } I_{l} \text {. }\end{array}$ & $\begin{array}{l}\text { For each } \mathrm{SN}_{k} \text { a matrix of process- } \\
\text { intensity-contingent state-transition proba- } \\
\text { bilities, } A_{\mathrm{SN}_{k}} \text {, is constructed, containing all } \\
\text { possible state-transition probabilities, } \\
p\left(\sigma_{h_{i}} \mid\left(\sigma_{h_{j}} \wedge I_{l}\right)\right) \forall h_{i}, \forall h_{j}, \forall l \\
\mathrm{l}=1, \ldots, \mathrm{L} \\
\text { Examples of such state-transition probabil- } \\
\text { ity matrices can found in Mazzorana et } \\
\text { al. (2011) }\end{array}$ \\
\hline 4 & $\begin{array}{l}\text { Determination through hydrodynamic } \\
\text { simulations of the stochastic spatial and } \\
\text { temporal evolution scheme of flood in- } \\
\text { undation, } E_{\mathrm{RS}} \mid I_{q_{j}, j} \text {, corresponding to } \\
\text { each individual input event } I_{q_{j}, j} \text { (com- } \\
\text { pare also Table 2) }\end{array}$ & $\begin{array}{l}\text { Interfacing the results of the hydrodynamic } \\
\text { simulations (intensity maps corresponding } \\
\text { to different time steps) with the matrices } \\
\text { of state-transition probabilities. Over time } \\
\text { different stochastic nodes may exhibit one } \\
\text { or more possible state transitions, } \sigma_{h_{j}} \rightarrow \\
\sigma_{h_{i}} \text {, with well-defined state-transition prob- } \\
\text { abilities according to the local intensity of } \\
\text { the process } I_{l} \text {. } \\
\text { For each concerned stochastic node- } \mathrm{SN}_{k}- \\
\text { an update from the old to possible new } \\
\text { states follows, determining a distinct con- } \\
\text { stellation of states (with defined proba- } \\
\text { bilities). The construction of } E_{\mathrm{RS}} \mid I_{q_{j}, j} \\
\text { proceeds by running different simulations, } \\
\text { each corresponding to a specific constella- } \\
\text { tion, staring from the state-transition time } \\
\text { step. }\end{array}$ & $\begin{array}{l}\text { For each input event } I_{q_{j}, j} \text { a stochastic } \\
\text { spatial and temporal evolution scheme of } \\
\text { flood inundation, } E_{\mathrm{RS}} \mid I_{q_{j}, j} \text {, is obtained, } \\
\text { i.e. a graph specifying through time the } \\
\text { probabilistic structure of the constellation } \\
\text { changes in the RS. Each constellation } \\
\text { change carries along different flood inten- } \\
\text { sity maps. A complete representation both } \\
\text { in a space and time of the flood hazard in } \\
\text { the RS results. }\end{array}$ \\
\hline $4 *$ & $\begin{array}{l}\text { Simplified version of step } 4 \text { for practical } \\
\text { purposes. } \\
\text { Determination of a reduced and approx- } \\
\text { imated stochastic structure of flood in- } \\
\text { undation through hydrodynamic simu- } \\
\text { lations, corresponding to each individ- } \\
\text { ual input event } I_{q_{j}, j} \text {. }\end{array}$ & $\begin{array}{l}\text { An ex ante assumption is introduced by fix- } \\
\text { ing the relevant states (which can be more } \\
\text { than one) for the entire event duration for } \\
\text { each } \mathrm{SN}_{k} \text {, which significantly reduces the } \\
\text { computational complexity. A reduced num- } \\
\text { ber of possible system constellations re- } \\
\text { sults, each with a defined probability. } \\
\text { Expert-based judgement is essential to ad- } \\
\text { just the level of simplification according to } \\
\text { the scope of the study (e.g. conventional } \\
\text { hazard mapping). }\end{array}$ & $\begin{array}{l}\text { For each input event } I_{q_{j}, j} \text { a simplified } \\
\text { stochastic structure of flood inundation } \\
\bar{E}_{\mathrm{RS}} \mid I_{q_{j}, j} \text { is obtained. }\end{array}$ \\
\hline
\end{tabular}




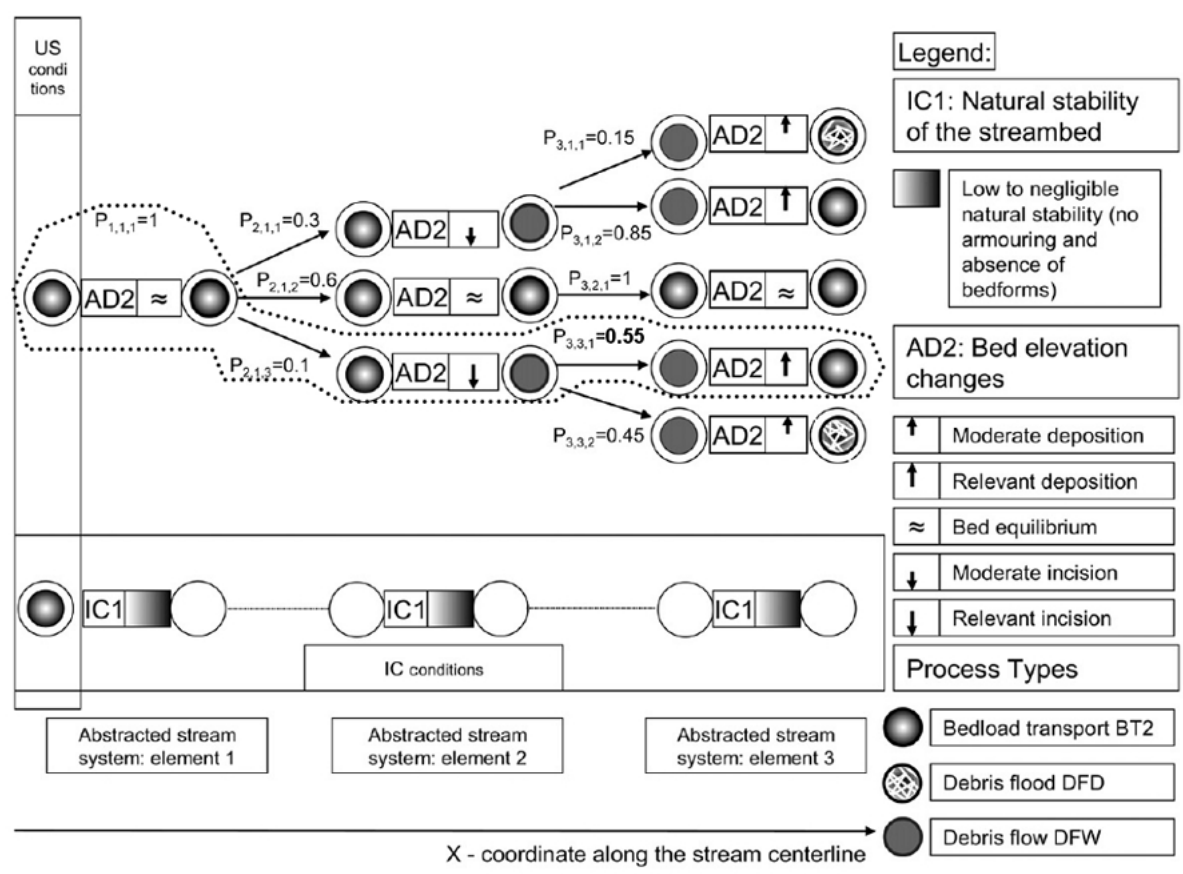

Fig. 2. Fully probabilised process routing scenario tree (modified from Mazzorana et al., 2012).

Table 4. Matrix of state-transition probabilities $A_{\mathrm{SN}_{1}}$.

\begin{tabular}{lllll}
\hline$A_{\mathrm{SN}_{1}}$ & $\sigma_{1} \stackrel{t r}{\longrightarrow} \sigma_{1}$ & $\sigma_{1} \stackrel{t r}{\longrightarrow} \sigma_{2}$ & $\sigma_{2} \stackrel{t r}{\longrightarrow} \sigma_{1}$ & $\sigma_{2} \stackrel{t r}{\longrightarrow} \sigma_{2}$ \\
\hline$h \leq h_{1}^{\prime}$ & 1 & 0 & 1 & 0 \\
$h_{1}^{\prime}<h \leq h_{2}^{\prime}$ & 0.5 & 0.5 & 0.5 & 0.5 \\
$h>h_{1}^{\prime}$ & 0 & 1 & 0 & 1 \\
\hline
\end{tabular}

respectively. It is assumed that $\mathrm{SN}_{1}$ and $\mathrm{SN}_{2}$ are subject to state-transitions, depending on local intensity levels of the flood resulting from flood propagation triggered by a specified input event, $I_{q_{j}, j}^{\mathrm{PR}}\left(\boldsymbol{x}_{N}, t\right)$, and occurring with a corresponding probability $\bar{P}_{q_{j}, j}^{\mathrm{PR}}$. It is further assumed that only two relevant states, $\sigma_{1}$ and $\sigma_{2}$, are possible for $\mathrm{SN}_{1}$ and $\mathrm{SN}_{2}$. The symbol $\sigma_{1}$ corresponds to the state "bridge unclogged" (i.e. flow section free for conveyance) and $\sigma_{2}$ corresponds to the state "bridge flow section clogged". In constructing the matrices of state-transition probabilities, $A_{\mathrm{SN}_{1}}$ and $A_{\mathrm{SN}_{2}}$, it is hypothesised that on the intensity side the statetransitions depend only on the local flow depths, $h\left(x_{\mathrm{SN} 1}, t\right)$ and $h\left(\boldsymbol{x}_{\mathrm{SN} 2}, t\right)$ (compare Tables 4 and 5).

The following stochastic spatiotemporal evolution scheme of flood inundation, $E_{\mathrm{RS}} \mid I_{q_{j}, j}$ may result (exemplified in Fig. 3).

We introduce the following indexing for the individual system configurations: $\operatorname{SC}_{\mathrm{Nr} . p r}\left(t_{k-1}\right), \operatorname{Nr}\left(t_{k}\right), t_{k}$, where $\operatorname{Nr} . \operatorname{pr}\left(t_{k-1}\right)$ is the identification number of the system configuration of the lower bound of the previous time step the current system configuration is linked to, $\operatorname{Nr}\left(t_{k}\right)$ is the
Table 5. Matrix of state-transition probabilities $A_{\mathrm{SN}_{2}}$.

\begin{tabular}{lllll}
\hline$A_{\mathrm{SN}_{2}}$ & $\sigma_{1} \stackrel{t r}{\longrightarrow} \sigma_{1}$ & $\sigma_{1} \stackrel{t r}{\longrightarrow} \sigma_{2}$ & $\sigma_{2} \stackrel{t r}{\longrightarrow} \sigma_{1}$ & $\sigma_{2} \stackrel{t r}{\longrightarrow} \sigma_{2}$ \\
\hline$h \leq h_{1}^{\prime \prime}$ & 1 & 0 & 1 & 0 \\
$h_{1}^{\prime \prime}<h \leq h_{2}^{\prime \prime}$ & 0.4 & 0.6 & 0.4 & 0.6 \\
$h>h_{1}^{\prime \prime}$ & 0 & 1 & 0 & 1 \\
\hline
\end{tabular}

identification number of the current configuration with respect to the other configurations arising at $t_{k}$, and $t_{k}$ indicates the lower bound of the current time step. The corresponding probability is identified by the compound probability of all SCs lying along a defined trajectory in the $E_{\mathrm{RS}} \mid I_{q_{j}, j}$ and is given by

$$
\begin{aligned}
& \bar{P}_{r, q_{j}, j}^{\mathrm{RS}}=\left(\bar{P}_{q_{j}, j}^{\mathrm{PR}}\right) \times \\
& \left\{\prod_{k=t_{0}}^{k=T} p\left[\mathrm{FP}_{r, q_{j}, t_{k}}^{\mathrm{RS}} \mid\left(\mathrm{SC}_{\mathrm{Nr} \cdot \mathrm{pr}\left(t_{k-1}\right), \mathrm{Nr}\left(t_{k}\right), t_{k}} \leftrightarrow \mathrm{SC}_{\mathrm{Nr} \cdot \operatorname{pr}\left(t_{k-2}\right), \operatorname{Nr}\left(t_{k-1}\right), t_{k-1}}\right)\right]\right\} .
\end{aligned}
$$

In Fig. 3, one such flood inundation trajectory, $\mathrm{FP}_{r, q_{j}, t_{k}}^{\mathrm{RS}}$, is contoured in dark red as an exemplification.

The spatiotemporal evolution schemes, $E_{\mathrm{RS}} \mid I_{q_{j}, j}$, associated with all input events $I_{q_{j}, j}^{\mathrm{PR}}\left(\boldsymbol{x}_{N}, t\right)$ are taken as starting point of the subsequent risk assessment presented in the next section.

For the analytic determination of both vulnerability and risk we simplify the notation that progressively indices the flood inundation trajectories of all $E_{\mathrm{RS}} \mid I_{q_{j}, j}$ with $j=$ $1, \ldots, M$ and denote accordingly the probability associated to 


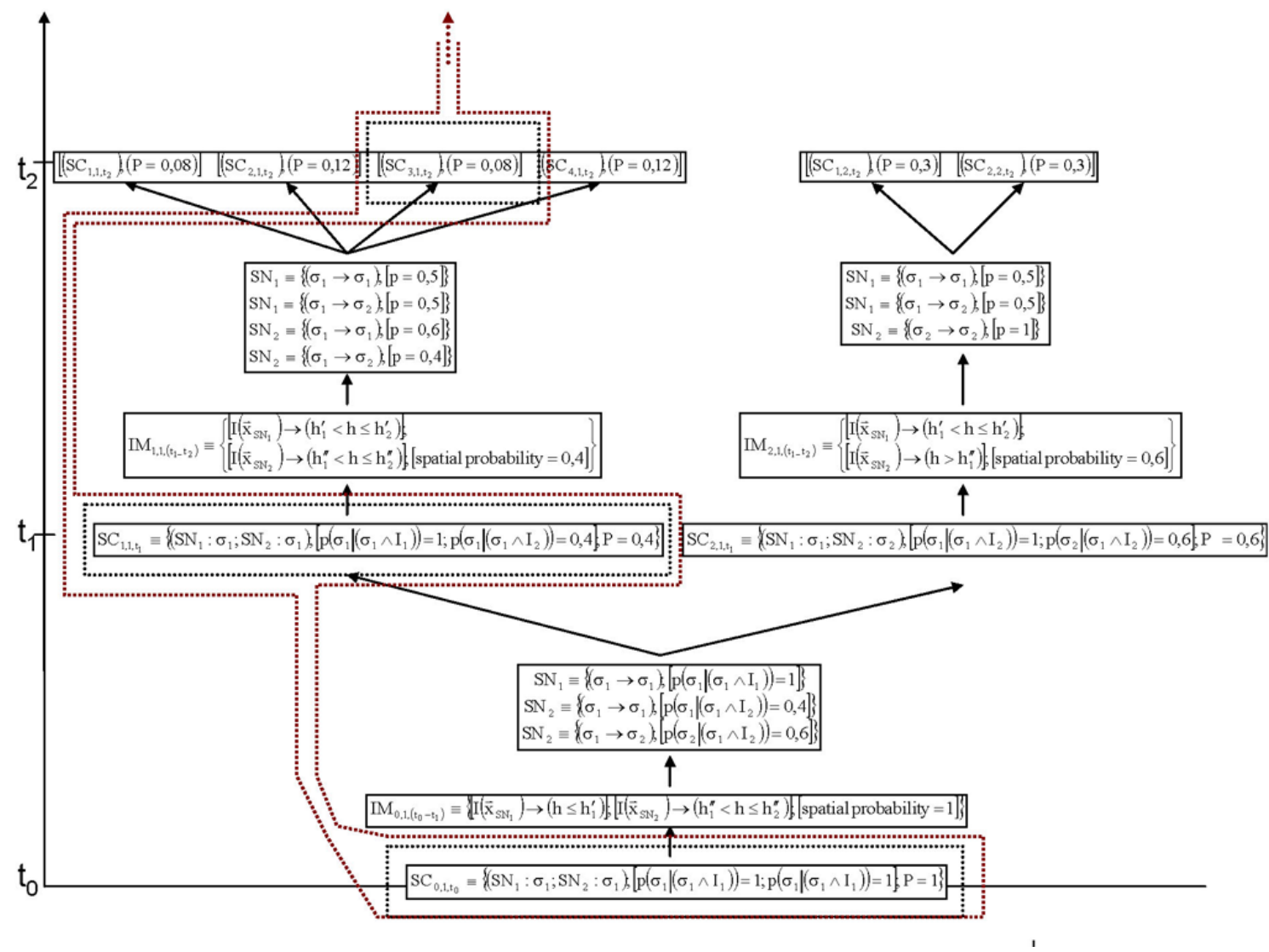

Fig. 3. Partial spatiotemporal evolution scheme of flood inundation $E_{\mathrm{RS}} \mid I_{q_{j}, j}$. Only two time steps are considered. SC stands for system configuration, subsuming the states of $\mathrm{SN}_{1}$ and $\mathrm{SN}_{2}$. IM stands for flood intensity map. For each SC, a distinct flood intensity map mirrors the flood evolution over time taking the results of the associated hydrodynamic simulation. Continuing this line of argument, for the time interval, $t_{2}-t_{3}$, six flood intensity maps represent the flood evolution. The spatial probability of each of these maps corresponds to the probability of the underlying SC. $t_{3}$ in this case identifies the point in time of the next state-transition occurring.

these trajectories by $p_{\mathrm{F}_{j}}$. Terminologically, instead of flood inundation trajectory the wording flood scenario will be used throughout.

The main results of the theoretical developments of flood hazard analysis were to show how to obtain for the considered RS fully probabilised $E_{\mathrm{RS}} \mid I_{q_{j}, j}$, entailing also as a result computed intensity maps (each one of which is valid for a specific timeframe within the event duration), corresponding to probabilised trajectories of flood inundation patterns characterized by determined system configuration changes. Expressed in a different way, a flood scenario $j$ is characterised by a succession in time of intensity maps $\mathrm{IM}_{j, \Delta t_{k}}$, occurring with probability $p_{\mathrm{F}_{j}}$, where $\Delta t_{k}$ indicates the timestep of validity of $\mathrm{IM}_{j, \Delta t_{k}}$ (compare Table 6).

\section{Assessment of elements at risk}

In the adopted conceptualisation of flood hazard risk (discussed in Sect. 6) the expected losses are expressed monetarily, which entails an economic valuation of damage.
Commonly flood damages can be classified into direct and indirect losses. While the former occur due to the physical contact (impact) of flood water with properties, people at risk, or any other object, the latter - although triggered by the direct impacts - are not spatially restricted to the flooded areas (Merz et al., 2010). Furthermore, indirect losses may extend well beyond the duration of the flood event. Depending on whether or not flood losses can be assessed in monetary values, a further distinction into tangible and intangible damages seems appropriate (Parker et al., 1987; Smith and Ward, 1998). More precisely, tangible damage is damage to capital stocks or resource flows which can be specified in monetary terms (e.g. buildings, infrastructure), whereas intangible damage is damage to assets which are not traded at a market and which is therefore challenging to be transferred into monetary values (e.g. eco-systemic externalities; Fuchs et al., 2007a). Although the terminology of this classification is commonplace, interpretations and delineations differ (Jonkman, 2007). 
Table 6. Matrix of successions of intensity maps $\mathrm{IM}_{j, \Delta t_{k}}$.

\begin{tabular}{llllllll}
\hline$\Delta t_{k} \downarrow \mid\left(j ; p_{\mathrm{F}_{j}}\right) \rightarrow$ & $\left(1 ; p_{\mathrm{F}_{1}}\right)$ & $\left(2 ; p_{\mathrm{F}_{2}}\right)$ & $\ldots$ & $\left(j ; p_{\mathrm{F}_{j}}\right)$ & $\ldots$ & $\left(M-1 ; p_{\mathrm{F}_{M-1}}\right)$ & $\left(M ; p_{\mathrm{F}_{M}}\right)$ \\
\hline$\Delta t_{1}$ & $\mathrm{IM}_{1, \Delta t_{1}}$ & $\mathrm{IM}_{2, \Delta t_{1}}$ & $\ldots$ & $\mathrm{IM}_{j, \Delta t_{1}}$ & $\ldots$ & $\mathrm{IM}_{M-1, \Delta t_{1}}$ & $\mathrm{IM}_{M, \Delta t_{1}}$ \\
$\Delta t_{2}$ & $\mathrm{IM}_{1, \Delta t_{2}}$ & $\mathrm{IM}_{2, \Delta t_{2}}$ & $\ldots$ & $\mathrm{IM}_{j, \Delta t_{2}}$ & & $\mathrm{IM}_{M-1, \Delta t_{2}}$ & $\mathrm{IM}_{M, \Delta t_{2}}$ \\
$\ldots$ & $\ldots$ & $\ldots$ & $\ldots$ & $\ldots$ & $\ldots$ & $\ldots$ & $\ldots$ \\
$\Delta t_{k}$ & $\mathrm{IM}_{1, \Delta t_{k}}$ & $\mathrm{IM}_{2, \Delta t_{k}}$ & & $\mathrm{IM}_{j, \Delta t_{k}}$ & & $\mathrm{IM}_{M-1, \Delta t_{k}}$ & $\mathrm{IM}_{M, \Delta t_{k}}$ \\
$\ldots$ & $\ldots$ & $\ldots$ & $\ldots$ & $\ldots$ & $\ldots$ & $\ldots$ & $\ldots$ \\
$\Delta t_{T-1}$ & $\mathrm{IM}_{1, \Delta t_{T-1}}$ & $\mathrm{IM}_{2, \Delta t_{T-1}}$ & & $\mathrm{IM}_{j, \Delta t_{T-1}}$ & & $\mathrm{IM}_{M-1, \Delta t_{T-1}}$ & $\mathrm{IM}_{M, \Delta t_{T-1}}$ \\
$\Delta t_{T}$ & $\mathrm{IM}_{1, \Delta t T}$ & $\mathrm{IM}_{2, \Delta t T}$ & & $\mathrm{IM}_{j, \Delta t T}$ & & $\mathrm{IM}_{M-1, \Delta t T}$ & $\mathrm{IM}_{M, \Delta t T}$ \\
\hline
\end{tabular}

In order to provide the optimal supply of protection against flood hazards, the public sector will need, among other information, evaluation of costs and benefits (Hanley and Spash, 1994). Costs are evaluated in terms of the present value of the previous investment so that the opportunity costs can be compared to the utility that would have resulted from an alternative allocation of the resources. Benefits are evaluated in terms of prevented damage due to the implementation of mitigation measures. Therefore, we put the distinction between tangibles and intangibles into a dynamic perspective. Environmental valuation is a rapidly expanding field (Perman et al., 2011). Refined valuation techniques, based on first principles such as willingness to pay (WTP) or willingness to accept (WTA) are in perpetual development (Fuchs et al., 2007a). An ever widening spectrum of non-market commodities and services are made accessible to economic valuation (Pommerehne and Römer, 1992; Perman et al., 2011). Different valuation principles are employed to attach values to distinct object categories (Drees and Paul, 2011; Perman et al., 2011). Operationally, we distinguish between object categories valued through economic approaches using market values (e.g. reinstatement value for structures) and object categories where contingent valuation $(\mathrm{CV})$ methods are applied due to missing market values (Pommerehne and Römer, 1992; Alberini et al., 2004). With reference to the former we introduce a general scheme to structurally dissect complex objects and make them accessible to economic valuation in risk assessment, while the latter is treated separately.

Hence, in dissecting a complex object (e.g. a production plant) we distinguish between:

1. vertically extending fixed structures (e.g. walls of the buildings) impacted directly by the flood process;

2. particular superstructures (e.g. roofs, decks) impacted rarely and mostly indirect by the flood process; and

3. installations and/or mobile objects (e.g. machines and cars) impacted mostly direct by the flood process.

For completeness, two supplementary categories are introduced that are affected by flooding as well as sediment and wood deposition processes:
4. surfaces (areas) for different land use purposes (e.g. agricultural land, but also parking areas and roads); and

5. biotic systems (e.g. wood, but also orchards).

The direct economic reference for a valuation of object parts belonging to the categories (1) (2) and (3) is the determination of the reinstatement value. As suggested by Gallerani et al. (2011), the reinstatement value can be calculated as construction value $-\mathrm{NV}-$ by

$\mathrm{NV}=\sum_{i=1}^{n} \sum_{j=1}^{m} q_{i j} \cdot p_{i}$,

where NV is the reinstatement value of the considered object; $q_{i j}$ is the required quantity of input $j$ to perform the construction workflow unit $i$; and $p_{i}$ is the unitary price of the construction workflow unit $i$.

For category (3) the estimation of the market value - MV - of the components of equipment is calculated as follows:

$\mathrm{MV}=C_{h} \cdot\left(1+\frac{M}{100}\right) \cdot \frac{D_{\mathrm{r}}}{D}$,

where MV is the most probable market value of the considered equipment component; $C_{h}$ is the purchase price; $M$ is the cost increment from the year of purchase to the year of valuation; $D_{\mathrm{r}}$ is the residual economic life (in years); and $D$ is the economic life span (in years);

In case of object category (5), the economic valuation is carried out by determining the capital value of the considered biotic system through suitable capitalisation formulas.

The economic valuation of people at risk needs a separate consideration. In this paper, people at risk are monetised by using the so-called value of statistical life as a typical nonmarket value (Leiter and Pruckner, 2005). This value of statistical life is defined as the rate at which people are willing to exchange income for a reduction in mortality risk. It is calculated by dividing the annual mean or median willingness to pay - WTP - through the corresponding risk variation. Several studies aimed at determining the value of statistical life have been conducted in different contexts (Viscusi and Aldy, 2003; Viscusi, 2008), such as snow avalanches, where the 
influence of implicit information associated with the occurrence of avalanches on WTP-values for risk prevention was quantified with a range between $€ 1.8$ and 5.2 million (Leiter and Pruckner, 2005), which is consistent with other studies (Alberini et al., 2004).

In general, three major interrelated requirements have to be met by the assessment of elements at risk exposed. These include (1) the risk mitigation performance of planned mitigation strategies, which should be quantified on a monetary basis (e.g. in terms of annual risk reduction); (2) the cost-plan for each strategy, which shall be considered from a life-cycle perspective; and (3) the net present value - NPV - associated with each mitigation alternative, which has to be determined in order to select the optimal risk management solution according to the assumed normative preferences of the public decision maker. Considering the peculiarities of public investment decisions to mitigate flood hazard risk, specifically the associated long-term capital commitments and the occurring interdependencies between these long-term commitments and important economic activities in mountain regions (above all arising from tourism economy and trading), the required analytical effort has to be balanced.

\section{Vulnerability of endangered elements}

Taking the perspective of natural sciences, and neglecting any social implications arising from flood hazards, vulnerability is considered as a functional relationship between process magnitude or intensity, the resulting impact on structural elements at risk, and exposed values. With respect to the built environment, vulnerability is related to the susceptibility of physical structures and is defined as the expected degree of loss resulting from the impact of a certain event on the elements at risk (Fuchs, 2009). Its assessment requires the evaluation of different parameters and factors such as the type of element at risk, resistance, and implemented protective measures (i.e. local structural protection, Holub and Fuchs, 2009; Holub et al., 2012).

For both the static and the dynamic conceptualisation of flood risk, the assessment of physical vulnerability is an essential requirement to quantify the expected damage in monetary terms. With respect to a static conceptualisation of flood risk, functional vulnerability approaches have been proposed only for a limited number of object categories (e.g. residential buildings, see Papathoma-Köhle et al., 2011, for an overview). In particular, vulnerability functions for buildings impacted by debris flows (Fuchs et al., 2007b; Akbas et al., 2009; Quan Luna et al., 2011) and fluvial sediment transport (Totschnig et al., 2011) are limited. In most of these studies vulnerability was measured using an economic approach and derived from the quotient between the loss and the individual reinstatement value for each element at risk considered. According to the debris flow hazards, the relationship between debris flow intensity in terms of deposit heights, $I_{\mathrm{DF}}\left(\boldsymbol{x}_{i}\right) \equiv h_{\mathrm{d}}\left(\boldsymbol{x}_{i}\right)$, at the location of the object, $\boldsymbol{x}_{i}$, and vulnerability, $v_{i}=v_{i}\left(h_{\mathrm{d}}\left(\boldsymbol{x}_{i}\right)\right)$, was found to fit best to the data by a second-order polynomial function for all intensities $h_{\mathrm{d}}\left(\boldsymbol{x}_{i}\right) \leq 2.5 \mathrm{~m}$, namely:

$v_{i}=v_{i}\left(h_{\mathrm{d}}\left(\boldsymbol{x}_{i}\right)\right)=0.11 \cdot h_{\mathrm{d}}^{2}\left(\boldsymbol{x}_{i}\right)-0.01 \cdot h_{\mathrm{d}}\left(\boldsymbol{x}_{i}\right)$.

According to the fluvial sediment transport phenomena, the best-fitting function was found to be the following:

$$
\begin{aligned}
v_{i}= & v_{i}\left(I_{\mathrm{R}_{\mathrm{ST}}}\left(\boldsymbol{x}_{i}\right)\right) \\
& -0.466\left(\frac{\tan \left(\frac{\left(I_{\mathrm{R}_{\mathrm{ST}}}\left(\boldsymbol{x}_{i}\right)\right) \cdot \pi}{2}\right)+0.395}{0.395}-1\right)^{-2.091}, \\
= & e^{-},
\end{aligned}
$$

where $I_{\mathrm{R}_{\mathrm{ST}}}\left(\boldsymbol{x}_{i}\right)$ is the relative intensity of the fluvial sediment transport process at the location of the object, $\boldsymbol{x}_{i}$, expressed as ratio between the deposit height $h_{\mathrm{d}}\left(\boldsymbol{x}_{i}\right)$ and the height of the considered building $H_{i}$.

In coherence with the variability in space and over time of the flood hazard process patterns in the response system, vulnerability might be conveniently assessed dynamically for each potentially impacted element at risk, $i=1, \ldots, N$, through a differential equation of the form:

$$
\frac{d v_{i}}{\mathrm{~d} t}=\psi_{i}\left(v_{i}, t\right) \cdot v_{i} \cdot\left(1-v_{i}\right), \quad \forall i,
$$

where $v_{i}$ is the vulnerability of the element at risk $i$. We assume the element at risk $i$ to be potentially movable, thus $\boldsymbol{x}_{i}=\boldsymbol{x}_{i}(t)$. This is to satisfy the general case of operational intervention plans, which are targeted at displacing objects exposed during a flood event towards safer locations (e.g. by evacuating people at risk to a shelter). In the simplest case of an a priori given, and thus deterministic, intervention plan the coordinates $\boldsymbol{x}_{i}=\boldsymbol{x}_{i}(t)$ of the object $i$ at different times are known in advance. Hence, we can conveniently define a location matrix $\bar{L}\left[\boldsymbol{x}_{i}(t)\right]$ as given in Table 7 .

The symbol $\psi_{i}$ is called "vulnerability functional", which can be intended as an element's specific vulnerability parameter. It is defined as follows:

$$
\psi_{i}=\frac{1}{\xi\left(v_{i}\right)} \cdot \frac{1}{2} \cdot \frac{c_{\mathrm{d}_{i}} \cdot \rho}{m_{i} \cdot g} \cdot \bar{h}_{i} \cdot b_{i} \cdot \bar{v}_{\perp i}^{2},
$$

where $c_{\mathrm{d}_{i}}$ is the drag coefficient of object $i, \rho$ is the density of the fluid, $m_{i}$ is the mass per unitary length of element at risk $i, \bar{h}_{i}$ is the maximum flow depth along the perimeter of the element at risk $i, b_{i}$ is the object's perimeter exposed to the flow and $\bar{v}_{\perp i}$ is the maximum velocity normal to the perimeter of the element at risk $i$.

Both $\bar{h}_{i}$ and $\bar{v}_{\perp i}$ can be computed for each timestep $\Delta t_{k}$ and for each flood scenario $j$ using the intensity maps $\mathrm{IM}_{j, \Delta t_{k}}$, which can be conveniently organized in a matrix as shown in Table 7. 
Table 7. Matrix of locations $\boldsymbol{x}_{i}=\boldsymbol{x}_{i}(t)$ (deterministic case).

\begin{tabular}{|c|c|c|c|c|c|c|c|}
\hline$\Delta t_{k} \downarrow \mid i \rightarrow$ & 1 & 2 & $\ldots$ & $i$ & $\ldots$ & $N-1$ & $N$ \\
\hline$\Delta t_{1}$ & $x_{1}, \Delta t_{1}$ & $\boldsymbol{x}_{2}, \Delta t_{1}$ & $\ldots$ & $\boldsymbol{x}_{i}, \Delta t_{1}$ & $\ldots$ & $\boldsymbol{x}_{N-1}, \Delta t_{1}$ & $\boldsymbol{x}_{N}, \Delta t_{1}$ \\
\hline$\Delta t_{2}$ & $x_{1}, \Delta t_{2}$ & $\boldsymbol{x}_{2}, \Delta t_{2}$ & $\ldots$ & $\boldsymbol{x}_{i}, \Delta t_{2}$ & & $\boldsymbol{x}_{N-1}, \Delta t_{2}$ & $\boldsymbol{x}_{N}, \Delta t_{2}$ \\
\hline$\ldots$ & $\ldots$ & $\ldots$ & $\ldots$ & $\ldots$ & $\ldots$ & $\ldots$ & $\ldots$ \\
\hline$\Delta t_{k}$ & $\boldsymbol{x}_{1}, \Delta t_{k}$ & $\boldsymbol{x}_{2}, \Delta t_{k}$ & & $\boldsymbol{x}_{i}, \Delta t_{k}$ & & $\boldsymbol{x}_{N-1}, \Delta t_{k}$ & $\boldsymbol{x}_{N}, \Delta t_{k}$ \\
\hline$\ldots$ & $\ldots$ & $\ldots$ & $\ldots$ & $\ldots$ & $\ldots$ & $\ldots$ & $\ldots$ \\
\hline$\Delta t_{T-1}$ & $\boldsymbol{x}_{1}, \Delta t_{T-1}$ & $\boldsymbol{x}_{2}, \Delta t_{T-1}$ & & $\boldsymbol{x}_{i}, \Delta t_{T-1}$ & & $\boldsymbol{x}_{N-1}, \Delta t_{T-1}$ & $\boldsymbol{x}_{N}, \Delta t_{T-1}$ \\
\hline$\Delta t_{T}$ & $x_{1}, \Delta t_{T}$ & $x_{2}, \Delta t_{T}$ & & $\boldsymbol{x}_{i}, \Delta t_{T}$ & & $\boldsymbol{x}_{N-1}, \Delta t_{T}$ & $\boldsymbol{x}_{N}, \Delta t_{T}$ \\
\hline
\end{tabular}

$\xi\left(v_{i}\right)$ is a function of the vulnerability at time $t$ of the considered element at risk $i$. A suitable functional form of $\xi\left(v_{i}\right)$ is: $\xi\left(v_{i}\right)=a_{i} \sqrt{1-v_{i}^{2}}$ with $a_{i}$ as an object-specific parameter to be determined empirically.

Considering Eq. (7), Eq. (6) can be conveniently re-written as (refer to Appendix A for mathematical details):

$$
\frac{d v_{i}}{\mathrm{~d} t}=\left(\frac{c_{\mathrm{d}_{i}} \cdot \rho}{2 \cdot a_{i} \cdot m_{i} \cdot g} \cdot \bar{h}_{i} \cdot b_{i} \cdot \bar{v}_{\perp i}^{2}\right) \cdot v_{i} \cdot \sqrt{\frac{1-v_{i}}{1+v_{i}}}
$$

or

$$
\begin{aligned}
& \frac{d v_{i}}{\mathrm{~d} t}=\psi_{i}^{*} \cdot v_{i} \cdot \sqrt{\frac{1-v_{i}}{1+v_{i}}} \\
& \text { with } \psi_{i}^{*}=\left(\frac{c_{\mathrm{d}_{i}} \cdot \rho}{2 \cdot a_{i} \cdot m_{i} \cdot g} \cdot \bar{h}_{i} \cdot b_{i} \cdot \bar{v}_{\perp i}^{2}\right) .
\end{aligned}
$$

Hence, on the basis of the fully probabilised flood scenarios (cf. Table 6) and the location matrix for all considered elements at risk (cf. Table 7) the pattern of vulnerability can be tracked for all considered elements in time for a given flood scenario by explicitly integrating the system of ordinary differential equations (compare Eq. 6) as follows:

$$
\begin{aligned}
& v_{i}\left(t_{k-1}+\Delta t_{k}\right)=v_{i}\left(t_{k-1}\right)+ \\
& \quad\left\{\psi_{i}\left(t_{k-1}\right) \cdot v_{i}\left(t_{k-1}\right) \cdot\left[1-v_{i}\left(t_{k-1}\right)\right]\right\} \cdot \Delta t_{k}, \forall i, \forall t_{k} .
\end{aligned}
$$

Operationally we proceed separately for each column of Table $7, j=1, \ldots, M$, calculating for each time step, $\Delta t_{k}$, through the system of Eq. (6) the vulnerability, $v_{i, j}\left(t_{k-1}+\Delta t_{k}\right)$, of each element at risk, $i=1, \ldots, N$, taking the flow depths, $\bar{h}_{i}$, and velocity, $\bar{v}_{\perp i}$, from the corresponding intensity map, $\mathrm{IM}_{j, \Delta t_{k}}$, at the object location coordinates $\boldsymbol{x}_{i}\left(t_{k}\right)$.

Nevertheless, empirical studies to fit the parameter value $a_{i}$ in $\xi\left(v_{i}\right)=a_{i} \sqrt{1-v_{i}^{2}}$ (cf. Eq. 7) are still missing. However, first estimates can be obtained by re-analysing the datasets used by Fuchs et al. (2007b) and Totschnig et al. (2011). In fact, knowing the duration of the analysed events, different trial values for $a_{i}$ can be tested until the calculated final vulnerability comes sufficiently close to the vulnerability assessed with the functional approaches of Eqs. (4) and (5). Without more accurate parameter estimations, the overall goal to dynamically analyse flood risk should be centred on tracing qualitative risk profiles (risk evolution over time) and not a quantification of risk in absolute terms. Nevertheless, despite this temporary limitation in the spectrum of applicability, the usefulness of the dynamic approach is undoubted, given in particular the identification of the socalled risk kernels and those tipping process patterns that induce detectable amplifications in risk. In other words, identifying those triggers of risk amplification within the event duration facilitates the definition of risk mitigation strategies aimed at their removal with a logical prioritisation. In this way, mirroring the risk evolution in space and over time, the proposed risk analytic tool becomes an exploratory planning toolkit in the crucial design phases. From a final project assessment perspective, we suggest (as long as the empirical body of knowledge for dynamic vulnerability assessment is not sufficiently large) to perform the risk computations by adopting the static conceptualisation of risk (see Eq. 4).

Although still roughly specified within risk analysis, structural vulnerability is understood here to be the source of any other type of vulnerability, since, following a temporal logic, if there was no impact due to a hazardous event on elements at risk, no loss would result (see Fuchs, 2009, for an extended string of argumentation), and the concerned society would not suffer harm.

\section{Risk assessment}

It has repeatedly been claimed that there is a particular lack of studies related to the temporal evolution of risk (Keiler et al., 2006; Fuchs and Keiler, 2008, 2013; Fuchs et al., 2008, 2012a), and the underlying vulnerability of values at risk and of communities (Fuchs, 2009; Fuchs et al., 2011, 2012b; Papathoma-Köhle et al., 2011). Therefore, based on the static and dynamic formalisations of vulnerability presented in the previous section, we introduce the static and dynamic notions of risk.

According to the static conceptualisations of natural hazard risk (Fuchs, 2009; Mazzorana and Fuchs, 2010a), risk for objects exposed to the impacts of flood hazard processes is quantified on an annual basis as follows: 


$$
R^{\mathrm{S}}=\sum_{j=1}^{j=M} p_{\mathrm{F}_{j}} \cdot \sum_{h=1}^{h=H}\left\{p_{E_{h}} \cdot \sum_{i=1}^{i=N}\left[\operatorname{ED}_{i, j, h}\left(I_{\mathrm{F}_{j}}\left(\boldsymbol{x}_{i, h}\right), s\right)\right]\right\}
$$

With reference to the static conceptualisation (superscript $\mathrm{S}), R^{\mathrm{S}}$ is the annual risk in terms of expected losses for the elements at risk $(i=1, \ldots, N)$ induced by the flood hazard scenarios $(j=1, \ldots, M)$ under the assumed exposure configuration $(h=1, \ldots, H)$.

The probability associated to a specific flood scenario is denoted by $p_{\mathrm{F}_{j}}$ and the probability of a given exposure configuration, namely a defined set of locations $-\boldsymbol{x}_{i, h} \forall i$ - of the considered elements at risk, is denoted by $p_{E_{h}}$. $\mathrm{ED}_{i, j, h}\left(I_{\mathrm{F}_{j}}\left(\boldsymbol{x}_{i, h}\right), s\right)$ is the expected damage (or loss expressed in monetary values) for an element at risk, given a maximum process intensity $I_{\mathrm{F}_{j}}$ in $\boldsymbol{x}_{i, h}$ resulting from the considered flood hazard scenario. In the adopted static notion of risk, $I_{\mathrm{F}_{j}}\left(\boldsymbol{x}_{i, h}\right)$ corresponds to the maximum intensity, $I_{\mathrm{F}_{j}}\left(\boldsymbol{x}_{i, h}\right)=\max \left(\operatorname{array}\left(\mathrm{IM}_{j, \Delta t_{k}}\left(\boldsymbol{x}_{i, h}\right)\right)\right)$, in terms of flow depths or flow velocities. Finally, $s$ is a Boolean variable aimed at identifying situations where mobile elements at risk are sheltered by enveloping objects (e.g. people within their residential buildings).

Formally, from an ex-ante perspective, the loss in value for a given element impacted by a flood event can be assumed to be equal to the depreciated value of the part of the element to be reinstated, hence:

$D_{i}=C_{i} \delta_{i}-\mathrm{RV}_{i}-\mathrm{SE}_{i}$,

where: $D_{i}$ is the monetary value of the losses attributable to flood impacts; $C_{i}$ are the reinstatement costs, namely the costs to substitute the damaged parts of the element by the corresponding new components; $\delta_{i}$ is a depreciation coefficient reflecting the obsolescence of the object; $\mathrm{RV}_{i}$ is the residual value of the damaged portion; and $\mathrm{SE}_{i}$ are the postevent expenditures for damage reduction.

To perform an ex-ante estimation of the expected damage - $\mathrm{ED}_{i, j, h}$ - we re-write the last equation introducing vulnerability functions instead, $v_{i, j, h}=v_{i}\left(I_{\mathrm{F}_{j}}\left(\boldsymbol{x}_{i, h}\right), s\right)$. These functions reflect, for a given intensity $-I_{\mathrm{F}_{j}}-$ of the considered flood hazard scenario (at the spatial location of the element at risk), the ratio between $C_{i}$ and the necessary (re-)construction costs of the entire element $\mathrm{NV}_{i}$. Neglecting from an ex-ante perspective the expected values of $\mathrm{RV}_{i}$ and $\mathrm{SE}_{i}$, the expected damage $-\mathrm{ED}_{i, j, h}$ - can be expressed as:

$\mathrm{ED}_{i, j, h}=v_{i}\left(I_{\mathrm{F}_{j}}\left(\boldsymbol{x}_{i, h}\right), s\right) \cdot \mathrm{NV}_{i} \cdot \delta_{i}$.

Now Eq. (10) can be re-written as:

$R^{\mathrm{S}}=\sum_{j=1}^{j=M} p_{\mathrm{F}_{j}} \cdot \sum_{h=1}^{h=H}\left\{p_{E_{h}} \cdot \sum_{i=1}^{i=N}\left[v_{i}\left(I_{\mathrm{F}_{j}}\left(\boldsymbol{x}_{i, h}\right), s\right) \cdot \mathrm{NV}_{i} \cdot \delta_{i}\right]\right\}$
Conversely, viewing risk from a dynamic standpoint implies incorporating the dynamic notion of vulnerability and thus mirroring, given a specified flood scenario, the evolution of the expected damage over time.

In this context the expected damage $\operatorname{ED}_{i, j, h}\left(t_{k-1}+\Delta t_{k}\right)$ for element at risk $i$ at a given time can be written as:

$\mathrm{ED}_{i, j, h}\left(t_{k-1}+\Delta t_{k}\right)=v_{i, j, h}\left(t_{k-1}+\Delta t_{k}\right) \cdot \mathrm{NV}_{i} \cdot \delta_{i}$.

Considering the expected damage for object $i$ under the hypothesis of different exposures we obtain:

$\mathrm{ED}_{i, j,(\forall h)}\left(t_{k-1}+\Delta t_{k}\right)=\mathrm{NV}_{i} \cdot \delta_{i} \cdot \sum_{h=1}^{h=H}\left(p_{E_{h}} \cdot v_{i, j, h}\left(t_{k-1}+\Delta t_{k}\right)\right)$

Taking into consideration the entire spectrum of flood hazard scenarios we can write:

$\mathrm{ED}_{i,(\forall j),(\forall h)}\left(t_{k-1}+\Delta t_{k}\right)=$

$\mathrm{NV}_{i} \cdot \delta_{i} \cdot \sum_{j=1}^{j=M}\left\{p_{\mathrm{F}_{j}} \cdot\left[\sum_{h=1}^{h=H}\left(p_{E_{h}} \cdot v_{i, j, h}\left(t_{k-1}+\Delta t_{k}\right)\right)\right]\right\}$

Extending the analysis to all objects at risk, the collective risk can be dynamically quantified as follows:

$R^{\mathrm{D}}\left(t_{k-1}+\Delta t_{k}\right)=\mathrm{ED}_{(\forall i),(\forall j),(\forall h)}\left(t_{k-1}+\Delta t_{k}\right)=$

$\sum_{i=1}^{i=N}\left\{\mathrm{NV}_{i} \cdot \delta_{i} \cdot \sum_{j=1}^{j=M}\left[p_{\mathrm{F}_{j}} \cdot\left(\sum_{h=1}^{h=H}\left(p_{E_{h}} \cdot v_{i, j, h}\left(t_{k-1}+\Delta t_{k}\right)\right)\right)\right]\right\}$.

The overall risk for all scenarios and over the entire flood duration can be, according to the dynamic conceptualisation (superscript D), determined as:

$R^{\mathrm{D}}=\mathrm{ED}_{(\forall i),(\forall j),(\forall h)}\left(t_{T-1}+\Delta t_{T}\right)$

or

$R^{\mathrm{D}}=$

$\sum_{i=1}^{i=N}\left\{\mathrm{NV}_{i} \cdot \delta_{i} \cdot \sum_{j=1}^{j=M}\left[p_{\mathrm{F}_{j}} \cdot\left(\sum_{h=1}^{h=H}\left(p_{E_{h}} \cdot v_{i, j, h}\left(t_{T-1}+\Delta t_{T}\right)\right)\right)\right]\right\}$.

The dynamic conceptualisation of risk and in particular Eq. (22) reflects the risk evolution over time. Throughout the risk genesis process it is possible to identify tipping process patterns that induce significant amplifications in risk.

\section{Economic assessment of risk mitigation strategies}

Flood mitigation strategies are considered to be public goods. In a narrower sense, they represent local public goods, because they benefit primarily the residential population. Flood mitigation measures have the following characteristics of public goods: For an inhabitant of a settlement, the quality of flood protection does not change by the utilisation of the same good by another inhabitant. The marginal costs of the 
utilisation of a flood protection measure by an additional user are zero and, as a consequence, there is no market price for this good. Consumption of the utility from this public good is not necessarily fully valued by the users and, as a result, the private sector fails to provide this good at a sufficient level for economic efficiency. In some cases, due to the scarcity of protected areas for development within floodplains, potential users could be excluded from the utilisation. This scarcity would make flood protection measures common (pool) resources, for which use by some decreases the potential utility to others (Mankiv, 2001). Related to the scarcity of development areas, and the possibility of an exclusion of potential users via market prices for scarce plots, flood protection measures can also be described as club goods, which is a special form of public goods (Fuchs and McAlpin, 2005).

Flood protection measures are also characterised by a non-excludability of the utilisation of the good (Fuchs and McAlpin, 2005). No user can exclude, independently of the individual willingness to pay, another user from utilization of flood protection such as levees. Non-excludability creates incentives for free riding because people can attain the utility of a good without paying for it. Free riding is a source of market failure because, since people pay for less than the efficient quantity of a good, the market produces less than the efficient quantity of the good. In our opinion, market failure is quite pervasive for a significant range of mitigation measures that are usually provided by the public administration.

Assuming that as a consequence of existing social needs a set of risk mitigation strategies $(z=1, \ldots, Z)$ has been designed for the analysed RS, an economic assessment is necessary to ensure allocative efficiency of the limited (monetary) resources available. To quantify the benefits of a given risk mitigation strategy, the equations for static or dynamic risk have to be re-applied to anticipate the risk mitigation performance of the designed strategy. Using $R$ to denote the risk in the reference situation (without implementation of the considered strategy) and $z$ to denote the remaining risk anticipating the effects of the implementation of strategy $z$, the annual benefit in terms of flood risk reduction can be formalised as follows:

with the static notion of risk:

$\Delta R^{\mathrm{S}}(R \rightarrow z)=R^{\mathrm{S}}(R)-R^{\mathrm{S}}(z)$

with the dynamic notion of risk:

$\Delta R^{\mathrm{D}}(R \rightarrow z)=R^{\mathrm{D}}(R)-R^{\mathrm{D}}(z)$.

To calculate $R^{\mathrm{S}}(z)$ or $R^{\mathrm{D}}(z)$, the entire procedure outlined above has to be repeated by including the risk mitigation strategy into the respective hydrological and hydraulic model, i.e. by adapting the digital terrain model accordingly. The implementation of such a strategy entails a series of costs over the planned life cycle. For analytic purposes it is convenient to specify the expenditure flows $-C(\mathrm{LC})_{\tau}^{z}-$ for each strategy $z$ over the life cycle duration $\mathrm{T}$ in form of a cost plan (compare Kruschwitz, 2008).
The Net Present Value NPV corresponding to each strategy $z$ is calculated as follows:

$\mathrm{NPV}^{R z}=\sum_{\tau=0}^{\tau=\mathrm{T}}\left\{\frac{\left[\Delta R^{\mathrm{S}}(R \rightarrow z)\right]-C(\mathrm{LC})_{\tau}^{z}}{(1+r)^{\tau}}\right\}$.

\section{Discussion and conclusions}

The historical shift of a traditionally agricultural society to a service industry and leisure-oriented society in Europe led to socio-economic developments in mountain environments and downstream riparian regions. This shift is reflected by an increasing usage of alpine areas and related forelands for settlement, industry, and recreation, particularly in the inner Alpine valleys with respect to tourism as well as in the large valleys and mountain forelands with respect to urbanisation. Consequently, this results in a conflict between human needs and their satisfaction and naturally determined conditions (Keiler and Fuchs, 2010).

Due to the implementation of the European Flood Risk Directive (Commission of the European Communities, 2007), the Member States are forced to base the management of natural hazards on the concept of risk, and to implement respective national legislations. Therefore, the issues discussed within this paper will provide important scientific fundamentals that should be considered when dealing with flood risk.

In the methodological section we elaborated a comprehensive chain of argumentations ranging from flood hazard assessment as an essential requisite for the subsequent risk assessment to the incorporation of the risk concept in the economic project assessment framework to evaluate designed risk mitigation strategies.

With respect to hazard analysis, the reduction of epistemic uncertainties routed in a basic lack of knowledge of fundamental phenomena (e.g. the possible range of rheological behaviour and the concentration of solids in the liquid-solid mixture of flow processes, clogging of critical flow sections due to transported driftwood and the protection systems' functionality and mitigation effectiveness) is made possible by following a structured procedure, outlined in Tables 1 , 2 and 3 . This procedure is dedicated to hydrological analyses, to the assessment of flood hazard scenarios within the loading system - LS - (i.e. between the confined part of a catchment, where water, sediment and wood fluxes are generated), and to the deduction of the inundation patterns in the response system - RS - (i.e. unconfined areas subject to flooding such as alluvial fans and floodplains).

In the subsequent sections we discussed the conceptualisations of static and dynamic vulnerability and risk. Contextually, we provided complete mathematical formalisations for use in risk assessment. The main conceptual difference between the two approaches to risk is that if risk is assessed dynamically, vulnerability of the elements at risk is assumed to be variable throughout the duration of the underlying flood 
inundation scenario. We formalised the structural vulnerability of an object impacted by the flood in terms of an ordinary differential equation. This equation used as a parameter a vulnerability functional depending on both, the local intensity of the flood and the vulnerability of the considered element at risk at a given point in time within the duration of the considered hazard scenario. On this basis, we derived mathematical expressions to mirror the evolution in terms of expected damage over time for the entire set of elements at risk. Given the spatiotemporal evolution patterns of flood hazard on the one hand and the corresponding profiles in terms of risk on the other hand, the identification of triggers for risk amplification and the definition of risk mitigation strategies are facilitated.

In addition to the traditional project assessment applications, the elaborated mathematical tools can be used as an exploratory planning toolkit in the project design phases. The conceptual structure for risk-based project assessment techniques presented in this paper can be further developed either in the field of risk analysis (e.g. Kappes et al., 2012) or in the field of rational decision making (e.g. Meyer et al., 2012). Concerning the former, new insights regarding dynamic risk analyses (i.e. parameter estimations) could be considered. With respect to the latter, decision theories can be explored by widening up the spectrum of applicability of the proposed framework (Holub and Fuchs, 2009).

Given these premises the following applicability spectrum is given:

1. The interplay between possible extensions of hazard zones - due to changes within the underlying design events (Holub and Fuchs, 2009), which may result from climate change but also from improvement in data mining - and the increased number of exposed buildings can be quantified.

2. The prioritisation of public investment flows for the mitigation of flood risk can be rationalised on the basis of risk-based decision making (Fuchs et al., 2009).

3. By using the risk concepts proposed, the benefits resulting from risk mitigation strategies in terms of achievable annual risk reduction can be monetarily quantified (Fuchs et al., 2007a).

4. In order to enhance the risk-based selection of optimal mitigation strategies, knowledge on the elements at risk exposed and their vulnerability is necessary (Fuchs et al., 2011). By the methods presented in Sect. 4 we illustrated how the value of the elements at risk can be determined. In Sect. 5 we considered existing functional approaches for the assessment of vulnerability with respect to a static conceptualisation of risk and provide theoretical extensions for the quantification of vulnerability within a dynamic context.
The quantification of risk, and risk management, promoted from a conceptual point of view, is linked to the sustainable development in mountain environments. Potentials and limitations which may occur due to mountain hazards under global change conditions, driven by both climate change and socio-economic development, may not be foreseen definitively and contain multiple aspects of uncertainty. As these uncertainties refer to aspects of magnitude and frequency, of probability of occurrence, and of vulnerability versus resilience, the concept of risk is becoming increasingly important and is a valuable basis for priority setting and further technical, financial and political decisions regarding the management of negative effects resulting from the impact of hazardous events.

\section{Appendix A}

\section{Mathematical background}

In this appendix we report some relevant results about the mathematical properties of the solution $v_{i}$ of the differential equation

$\frac{d v_{i}}{\mathrm{~d} t}=\psi_{r, i} \cdot \psi_{l, i} \cdot v_{i} \cdot \sqrt{\frac{1-v_{i}}{1+v_{i}}}$,

where

$\psi_{r, i}=\frac{1}{a_{i} \cdot m_{i} \cdot g}$

$\psi_{l, i}(t)=\frac{1}{2} \rho \cdot c_{\mathrm{d}_{i}} \cdot h_{i}(t) \cdot b_{i} \cdot \bar{v}_{\perp i}^{2}(t)$.

$\psi_{r, i}$ is a constant representing the resistance of the element exposed to flood impacts ( $m_{i}$ is the object's mass, $g$ is the standard gravity and $a_{i}$ is a coefficient accounting for the objects resistance characteristics), while $\psi_{l, i}$ is the timevarying drag force (here $\rho$ is the density of the fluid, $c_{\mathrm{d}_{i}}$ is the drag coefficient, $b_{i}$ is the object's perimeter exposed to the flow and $h_{i}(t), \bar{v}_{\perp i}(t)$ are, respectively, the timevarying (maximum) flow depth and normal velocity along the perimeter of the considered object).

Since $v_{i}$ represents the object's vulnerability, it only makes sense to consider values of this variable in the interval $[0,1]$. From a mathematical point of view, Eq. (A1) is an ordinary differential equation in normal form. Since the righthand side is Lipschitz outside the point $v_{i}=1$, any Cauchy problem associated to Eq. (A1) admits a unique solution for any initial value $v_{i}(0)=v_{i}^{0}$ with $v_{i}^{0} \neq 1$. Note however that by Eq. (A1), it does not make sense to have $v_{i}^{0}=0$, since in this case the only solution would be $v_{i}(t)=0$ for any $t$. Also, if there exists a time $\hat{t}$ such that $v_{i}(\hat{t})=1$, meaning that at time $\hat{t}$ the object is completely destroyed, the only sensible solution is to have $v_{i}(t)=1$ for any $t \geq \hat{t}$. 
From Eq. (A1) the solution $v_{i}$ is strictly increasing (if we suppose that $h_{i}(t)>0$ and $\bar{v}_{\perp i}(t) \neq 0$ for any $t$ in the considered time interval). In fact it is possible to find both lower and upper bounds for the solution by bounding the right-hand side of Eq. (A1). Since the values of $v_{i}$ are positive, the solution has to satisfy the following differential inequality:

$\frac{d v_{i}}{\mathrm{~d} t} \leq \psi_{i}(t) \cdot v_{i} \cdot \sqrt{1-v_{i}}$,

where for simplicity we have defined $\psi_{i}(t)=\psi_{r, i} \cdot \psi_{l, i}(t)$. The following Cauchy problem

$\left\{\begin{array}{c}\frac{d y_{i}}{\mathrm{~d} t}=\psi_{i}(t) \cdot v_{i} \cdot \sqrt{1-v_{i}} \\ y_{i}(0)=v_{i}^{0}\end{array}\right.$

can be solved analytically by separation of variables. Setting

$\varphi_{i}=\int_{0}^{t} \psi_{i}(s) d s, \quad k_{0}=\frac{1-\sqrt{1-v_{i}^{0}}}{1+\sqrt{1-v_{i}^{0}}}$

the solution of Eq. (A2) is

$\bar{v}_{i}^{u}=4 k_{0} \cdot \frac{e^{\varphi_{i}(t)}}{\left(1+k_{0} \cdot e^{\varphi_{i}(t)}\right)^{2}}$.

In a similar way, since we are interested in solutions having values lower than one, these will satisfy

$\frac{d v_{i}}{\mathrm{~d} t} \geq \psi_{i}(t) \cdot v_{i} \cdot \sqrt{1-v_{i}} \cdot \frac{1}{\sqrt{2}}$.

The Cauchy problem

$\left\{\begin{array}{c}\frac{d y_{i}}{\mathrm{~d} t}=\frac{1}{\sqrt{2}} \cdot \psi_{i}(t) \cdot v_{i} \cdot \sqrt{1-v_{i}} \\ y_{i}(0)=v_{i}^{0}\end{array}\right.$

admits the following solution

$\bar{v}_{i}^{l}=4 k_{0} \cdot \frac{e^{\frac{\varphi_{i}(t)}{\sqrt{2}}}}{\left(1+k_{0} \cdot e^{\frac{\varphi_{i}(t)}{\sqrt{2}}}\right)^{2}}$.

Thus, whenever the values of $v_{i}$ are in the interval $(0,1)$, i.e. for $t \in\left\{t \in[0, T]: v_{i}(t) \in(0,1)\right\}$ the following limitation holds

$\bar{v}_{i}^{l}(t) \leq v_{i}(t) \leq \bar{v}_{i}^{u}(t)$.

Using the above limits, it is then possible to predict, once $\psi_{i}$ is known, if the object will be destroyed at the end of the observation time, to have estimates on the time it takes to get damages greater than some prescribed level or to have upper and lower bounds on the vulnerability at the final observation time $T$.

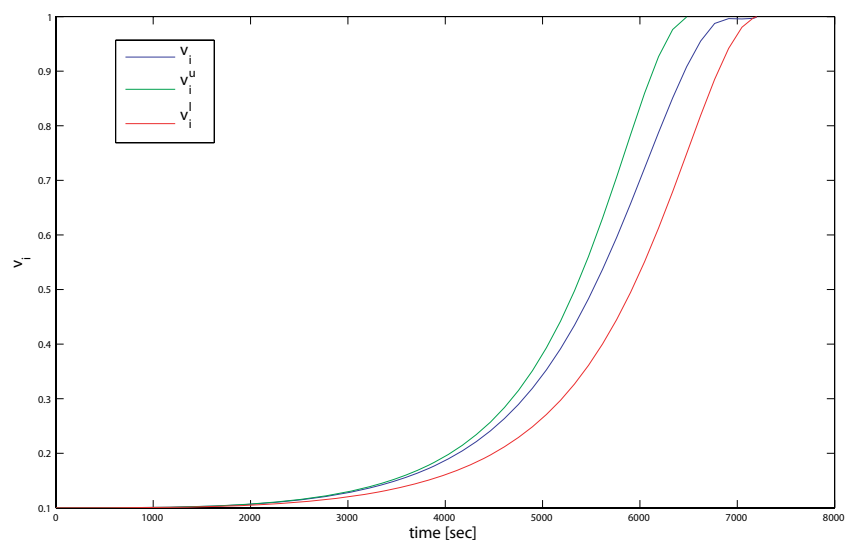

Fig. A1. Comparison of $v_{i}, v_{i}^{u}$ and $v_{i}^{l}$ for the following set of parameters: $m_{i}=25000 \mathrm{~kg}, \rho=1000 \mathrm{~kg} \mathrm{~m}^{-3}, c_{\mathrm{d}_{i}}=1, a_{i}=$ $0.025 \mathrm{~s}, k_{\mathrm{s}}=35 \frac{1}{\mathrm{~m}^{\frac{1}{3}} \cdot s}, i=0.002$ and supposing that $h_{i}(t)$ has linear growth, is zero at initial time and reaches $2.5 \mathrm{~m}$ in $7200 \mathrm{~s}$.

We also have

$\frac{d^{2} v_{i}}{\mathrm{~d} t^{2}}=v_{i}\left(-\psi_{i}^{2} \cdot \frac{v_{i}^{2}+v_{i}-1}{\left(v_{i}+1\right)^{2}}+\frac{d \psi_{i}}{\mathrm{~d} t} \cdot \sqrt{\frac{1-v_{i}}{1+v_{i}}}\right)$.

The first term in the parentheses switches from positive to negative values for $v_{i}=\hat{v}=\frac{\sqrt{5}-1}{2}$. The sign of the second one depends on the derivative of $\psi_{i}$ : if in the observation interval this function is non-decreasing, i.e. we are just considering the flood event, there will exist a value $\bar{v}_{i}<\hat{v}$ such that the second derivative of $v_{i}$ is zero if $\bar{v}_{i}$ is the image of the function $v_{i}$. We then have two cases: either $v_{i}$ is convex in the whole interval and $v_{i}<\bar{v}_{i}$ or there exists an inflection point at the time where the value of $v$ reaches $\bar{v}_{i}$ and then $v_{i}$ becomes concave.

If, for example, we assume uniform flow conditions in a wide rectangular channel (i.e. a river corridor), we can approximate the flow velocity using the formula

$\bar{v}_{\perp i}=k_{\mathrm{S}} \cdot h_{i}(t)^{2 / 3} \cdot i_{f}^{\frac{1}{2}}$,

where $k_{\mathrm{S}}$ is the Strickler roughness coefficient and $i_{f}$ the slope. Then we have

$\psi(t) \approx \frac{1}{a_{i} \cdot m_{i} \cdot g} \cdot \frac{1}{2} \rho \cdot c_{\mathrm{d}_{i}} \cdot k_{\mathrm{s}}^{2} \cdot h_{i}(t)^{\frac{7}{3}} \cdot b_{i} \cdot i_{f}$.

If $h_{i}$ is increasing linearly in $t$, i.e. $h_{i}(t)=\alpha t$ we obtain

$\varphi_{i}(t)=\frac{1}{a_{i} \cdot m_{i} \cdot g} \cdot \frac{1}{2} \rho \cdot c_{\mathrm{d}_{i}} \cdot \frac{3}{10} \cdot \frac{1}{\alpha} \cdot k_{\mathrm{s}}^{2} \cdot h_{i}(t)^{\frac{10}{3}} \cdot b_{i} \cdot i_{f}$.

Then, considering different slopes or growth rates for $h_{i}$, the effect of the shape of both the two limiting curves and the vulnerability itself, is that of a rescaling of the time variable (compare Fig. A1). 
Acknowledgements. The authors wish to kindly acknowledge M. Papathoma-Köhle, C. Scherer and A. Zischg for their constructive suggestions improving earlier versions of this manuscript. The research for this work received funding from the Austrian Science Fund (FWF): L535-N10.

Edited by: T. Glade

Reviewed by: M. Papathoma-Koehle and one anonymous referee

\section{References}

Akbas, S. O., Blahut, J., and Sterlacchini, S.: Critical assessment of existing physical vulnerability estimation approaches for debris flows, in: Proceedings of landslide processes: From geomorphologic mapping to dynamic modeling, edited by: Malet, J. P., Remaitre, A., and Bogaard, T., Strasburg, France, 6-7 February 2009, 229-233, 2009.

Alberini, A., Cropper, M., Krupnick, A., and Simon, N. B.: Does the value of a statistical life vary with age and health status? Evidence from the US and Canada, J. Environ. Econom. Manage., 48, 769-792, 2004.

Barredo, J.: Major flood disasters in Europe: 1950-2005, Nat. Hazards, 42, 125-148, 2007.

Comiti, F., Mao, L., Preciso, E., Picco, L., Marchi, L., and Borga, M.: Large wood and flash floods: evidences from the 2007 event in the Davca basin (Slovenia), in: Monitoring, Simulation, Prevention and Remediation of Dense and Debris Flow II, edietd by: De Wrachien, D., Lenzi, M. A., and Brebbia, C. A., WIT-Press, Southampton, 173-182, 2008.

Commission of the European Communities: Communication from the Commission to the Council, the European Parliament, the European Economic and Social Committee and the Committee of the Regions, Flood risk management Flood prevention, protection and mitigation, available at: http://eurlex.europa.eu/LexUriServ/LexUriServ.do\%3furi1/ 4COM:2004:0472:fin:en:pdf (last access: 27 October 2011), 2004.

Commission of the European Communities: Directive 2007/60/EC of the European Parliament and of the Council of 23 October 2007 on the assessment and management of flood risks, available at: http://eurlex.europa.eu/LexUriServ/LexUriServ. do\%3furi1/4OJ:L:2007:288:0027:0034:en:pdf (last access: 12 October 2011), 2007.

Drees, G. and Paul, W: Kalkulation von Baupreisen, Beuth Verlag, Berlin, 2011.

Eisenführ, F., Weber, M., and Langer, T.: Rational decision making, Berlin, Springer, 2010.

Fuchs, S.: Susceptibility versus resilience to mountain hazards in Austria - paradigms of vulnerability revisited, Nat. Hazards Earth Syst. Sci., 9, 337-352, doi:10.5194/nhess-9-337-2009, 2009.

Fuchs, S. and Keiler, M.: Variability of natural hazard risk in the European Alps: evidence from damage potential exposed to snow avalanche, in: Disaster management handbook, edited by: Pinkowski, J., CRC Press and Taylor \& Francis, Boca Raton and London, 267-279, 2008.

Fuchs, S. and Keiler, M.: Space and time: coupling dimensions in natural hazard risk management?, in: The spatial dimension of risk - how geography shapes the emergence of riskscapes, edited by: Müller-Mahn, D., Earthscan, London, 189-201, 2013.

Fuchs, S. and McAlpin, M. C.: The net benefit of public expenditures on avalanche defence structures in the municipality of Davos, Switzerland, Nat. Hazards Earth Syst. Sci., 5, 319-330, doi:10.5194/nhess-5-319-2005, 2005.

Fuchs, S., Bründl, M., and Stötter, J.: Development of avalanche risk between 1950 and 2000 in the Municipality of Davos, Switzerland, Nat. Hazards Earth Syst. Sci., 4, 263-275, doi:10.5194/nhess-4-263-2004, 2004.

Fuchs, S., Keiler, M., Zischg, A., and Bründl, M.: The long-term development of avalanche risk in settlements considering the temporal variability of damage potential, Nat. Hazards Earth Syst. Sci., 5, 893-901, doi:10.5194/nhess-5-893-2005, 2005.

Fuchs, S., Thöni, M., McAlpin, M. C., Gruber, U., and Bründl, M.: Avalanche hazard mitigation strategies assessed by cost effectiveness analysis and cost benefit analysis - Evidence from Davos, Switzerland, Nat. Hazards, 41, 113-129, 2007 a.

Fuchs, S., Heiss, K., and Hübl, J.: Towards an empirical vulnerability function for use in debris flow risk assessment, Nat Hazards Earth Syst. Sci., 7, 495-506, doi:10.5194/nhess-7-4952007, 2007b.

Fuchs, S., Kaitna, R., Scheidl, C., and Hübl, J.: The application of the risk concept to debris flow hazards, Geomech. Tunnell., 1, 120-129, 2008.

Fuchs, S., Spachinger, K., Dorner, W., Rochman, J., and Serrhini, K.: Evaluating cartographic design in flood risk mapping, Environ. Hazards, 8, 52-70, 2009.

Fuchs, S., Kuhlicke, C., and Meyer, V.: Editorial to the special issue: Vulnerability to natural hazards - the challenge of integration, Nat. Hazards, 58, 609-619, 2011.

Fuchs, S., Ornetsmüller, C., and Totschnig, R.: Spatial scan statistics in risk assessment - an application on vulnerability to mountain hazards, Nat. Hazards, 64, 2129-2151, 2012a.

Fuchs, S., Birkmann, J., and Glade, T.: Vulnerability assessment in natural hazard and risk analysis - current approaches and future challenges, Nat. Hazards, 64, 1969-1975, 2012b.

Gallerani, V., Viaggi, D., and Zanni, G.: Manuale di estimo, McGraw-Hill, Milano, 2011.

Hanley, N. and Spash, C.: Cost-benefit analysis and the environment, Cheltenham, Edward Elgar, 1994.

Holub, M. and Fuchs, S.: Mitigating mountain hazards in Austria - legislation, risk transfer, and awareness building, Nat. Hazards Earth Syst. Sci., 9, 523-537, doi:10.5194/nhess-9-5232009, 2009.

Holub, M., Suda, J., and Fuchs, S.: Mountain hazards: reducing vulnerability by adapted building design, Environ. Earth Sci., 66, 1853-1870, 2012.

Hübl, J., Bunza, G., Hafner, K., and Klaus, W.: ETAlp - Erosion, Transport in Alpinen Systemen "Stummer Zeugen Katalog”, Wien, Projektteam ETAlp, 2003.

International Standards Organisation: ISO 31000:2009, Risk management - Principles and guidelines, ISO, Geneva, 2009.

Jonkman, S. N.: Loss of life estimation in flood risk assessment, $\mathrm{PhD}$ thesis, Delft University, Delft, 2007.

Kappes, M., Keiler, M., von Elverfeldt, K., and Glade, T.: Challenges of analyzing multi-hazard risk: a review, Nat. Hazards, 64, 1925-1958, 2012. 
Keiler, M.: Development of the damage potential resulting from avalanche risk in the period 1950-2000, case study Galtür, Nat. Hazards Earth Syst. Sci., 4, 249-256, doi:10.5194/nhess-4-2492004, 2004.

Keiler, M. and Fuchs, S.: Berechnetes Risiko, Mit Sicherheit am Rande der Gefahrenzone, in: Geographische Risikoforschung, Zur Konstruktion verräumlichter Risiken und Sicherheiten, edited by: Egner, H. and Pott, A., Stuttgart, Franz Steiner, 5168, 2010.

Keiler, M., Zischg, A., Fuchs, S., Hama, M., and Stötter, J.: Avalanche related damage potential - changes of persons and mobile values since the mid-twentieth century, case study Galtür, Nat. Hazards Earth Syst. Sci., 5, 49-58, doi:10.5194/nhess-5-492005, 2005.

Keiler, M., Sailer, R., Jörg, P., Weber, C., Fuchs, S., Zischg, A., and Sauermoser, S.: Avalanche risk assessment - a multi-temporal approach, results from Galtür, Austria, Nat. Hazards Earth Syst. Sci., 6, 637-651, doi:10.5194/nhess-6-637-2006, 2006.

Keiler, M., Knight, J., and Harrison, S.: Climate change and geomorphological hazards in the eastern European Alps, Philos. Trans. Roy. Soc. London, 368, 2461-2479, 2010.

Kienholz, H., Krummenacher, B., Kipfer, A., and Perret, S.: Aspects of integral risk management in practice - Considerations with respect to mountain hazards in Switzerland, Österreichische Wasser- und Abfallwirtschaft, 56, 43-50, 2004.

Kruschwitz, L.: Investitionsrechnung, München, Oldenbourg, 2008.

Länger, E.: Der forsttechnische Dienst für Wildbach- und Lawinenverbauung in Österreich und seine Tätigkeit seit der Gründung im Jahre 1884, Teil 1: Textband, Dissertation, Universität für Bodenkultur, Wien, 2003.

Leiter, A. and Pruckner, G.: Dying in an avalanche: Current risks and valuation, The University of Adelaide Working Paper 200516, Adelaide: University of Adelaide, 2005.

Mankiv, N.: Grundzüge der Volkswirtschaftslehre, Stuttgart: Schäffer-Poeschl, 2001.

Mazzorana, B. and Fuchs, S.: Fuzzy formative scenario analysis for woody material transport related risks in mountain torrents, Environ. Model. Softw., 25, 1208-1224, 2010a.

Mazzorana, B. and Fuchs, S.: A conceptual planning tool for hazard and risk management, in: Internationales Symposion Interpraevent in the Pacific Rim, edited by: Chen, S.-C., Klagenfurt: Internationale Forschungsgesellschaft Interpraevent, 828837, 2010b.

Mazzorana, B., Hübl, J., and Fuchs, S.: Improving risk assessment by defining consistent and reliable system scenarios. Natural Hazards and Earth System Sciences, 9, 145-159, 2009.

Mazzorana, B., Comiti, F., Volcan, C., and Scherer, C.: Determining flood hazard patterns through a combined stochasticdeterministic approach, Nat. Hazards, 59, 301-316, 2011.

Mazzorana, B., Comiti, F., and Fuchs, S.: A structured approach to enhance flood hazard assessment in mountain streams, Nat. Hazards, online first, doi:10.1007/s11069-011-9811-y, 2011.
Mazzorana, B., Comiti, F., Scherer, C., and Fuchs, S.: Developing consistent scenarios to assess flood hazards in mountain streams, J. Environ. Manage., 94, 112-124, 2012.

Merz, B., Kreibich, H., Schwarze, R., and Thieken, A.: Review article "Assessment of economic flood damage;,; Nat. Hazards Earth Syst. Sci., 10, 1697-1724, doi:10.5194/nhess-10-16972010, 2010.

Meyer, V., Kuhlicke, C., Luther, J., Fuchs, S., Priest, S., Dorner, W., Serrhini, K., Pardoe, J., McCarthy, S., Seidel, J., Palka, G., Unnerstall, H., Viavattene, C., and Scheuer, S.: Recommendations for the user-specific enhancement of flood maps, Nat. Hazards Earth Syst. Sci., 12, 1701-1716, doi:10.5194/nhess-121701-2012, 2012.

Mitchell, J.: European river floods in a changing world, Risk Analys., 23, 567-574, 2003.

ONR, Österreichisches Normungsinstitut: Schutzbauwerke der Wildbachverbauung e Begriffe und ihre Definitionen sowie Klassifizierung, ONR 24800, Österreichisches Normungsinstitut, Wien, 2009.

Papathoma-Köhle, M., Kappes, M., Keiler, M., and Glade, T.: Physical vulnerability assessment for alpine hazards: state of the art and future needs, Nat. Hazards, 58, 645-680, 2011.

Parker, D. J., Green, C. H., and Thompson, P. M.: Urban flood protection benefits: A project appraisal guide, Aldershot, Gower Technical Press, 1987.

Perman, R., Ma, Y., Common, M., Maddison, D., and McGilvray, J.: Natural resource and environmental economics, Essex, AddisonWesley/Pearson, 2011.

Pommerehne, W. and Römer, A.: Ansätze zur Erfassung der Präferenzen für öffentliche Güter, Jahrbuch für Sozialwissenschaft, 43, 171-210, 1992

Quan Luna, B., Blahut, J., van Westen, C. J., Sterlacchini, S., van Asch, T. W. J., and Akbas, S. O.: The application of numerical debris flow modelling for the generation of physical vulnerability curves, Nat. Hazards Earth Syst. Sci., 11, 2047-2060, doi:10.5194/nhess-11-2047-2011, 2011.

Smith, K. and Ward, R.: Floods: Physical processes and human impacts, Chichester, John Wiley and Sons, 1998.

Totschnig, R., Sedlacek, W., and Fuchs, S.: A quantitative vulnerability function for fluvial sediment transport, Nat. Hazards, 58, 681-703, 2011.

United Nations: Resolutions adopted by the conference, Report of the United Nations conference on environment and development, 1993, 1, United Nations, New York, 1993.

Viscusi, W. K.: How to value a life, Vanderbilt Law and Economics Research Paper, 8-16, 2008.

Viscusi, W. K. and Aldy, J.: The value of a Statistical Life: A critical review of market estimates throughout the world, J. Risk Uncertain., 27, 5-76, 2003.

Zischg, A., Fuchs, S., Keiler, M., and Stötter, J.: Temporal variability of damage potential on roads as a conceptual contribution towards a short-term avalanche risk simulation, Nat. Hazards Earth Syst. Sci., 5, 235-242, doi:10.5194/nhess-5-235-2005, 2005. 